\title{
Winter-Spring Precipitation Variability in Pakistan
}

\author{
Iftikhar Ahmad1, Romana Ambreen1, Zhaobo Sun2, Weitao Deng2 \\ ${ }^{1}$ Department of Geography, University of Balochistan, Quetta, Pakistan \\ ${ }^{2}$ Key Laboratory of Meteorological Disaster, Ministry of Education, Nanjing University of Information Science \& \\ Technology, Nanjing, China \\ Email: 2360238iftigeog@gmail.com, iftigeog@gmail.com
}

Received 7 January 2015; accepted 24 March 2015; published 27 March 2015

Copyright (C) 2015 by authors and Scientific Research Publishing Inc.

This work is licensed under the Creative Commons Attribution International License (CC BY). http://creativecommons.org/licenses/by/4.0/

(c) (i) Open Access

\section{Abstract}

This study investigates the spatial-temporal variability of winter-spring (February-March-April) precipitation (WSP) in Pakistan over the period of 1961-2006 by making use of Empirical Orthogonal Function (EOF). The EOF analysis is based on ground observed data, reanalysis NCEP/NCAR of various geopotential heights and NOAA extended reconstructed sea surface temperatures (ERSST.v3). The significant modes are obviously variable at interannual time scale. The leading mode shows the node of maximum spatial variability anchored over the Peshawar Valley and Azad Kashmir (PVAK) axis. The pattern is associated with strong (weak) westerly jet over the Middle East. The pattern is also found closely associated with post monsoon and early winter El Niño. The Niño4 index can be an appropriate predictor for the first consistent single node pattern. The second significant mode represents a tripole pattern with areas of prominent variability over northwestern Pakistan, Quetta-Kalat region and northeastern Punjab. The pattern is found to be pro-NAO and in relation to this pattern, warm and stable SST anomalies appearing in the southern mid-latitudes of Indian and Atlantic basins.

\section{Keywords}

Pakistan, Winter-Spring Precipitation, EOF, Spatial Variability, Interannual Variability

\section{Introduction}

In the wake of 1997-1998 ENSO, world wide climatic repercussions were felt, South West Asia were subjected to sever drought [1] [2]. The Fourth Assessment Report of IPCC [3] projects that variability and change in climate will further aggravate floods and droughts in Asia and will increase vulnerability of poor Asian communities to the extreme weather events. ENSO induced climate variability at regional scale effect the agricultural 
production [4], its impact was felt on agriculture of Pakistan during the subsequent period of 1998-2002. Sixth in rank of global population [5], agriculture based economy and transformation from rural to urban way of life in Pakistan exert much pressure on river Indus and its tributaries which fetch water from northern and western mountains of Pakistan. The northern and northwestern Pakistan accumulates substantial amount of precipitation during winter which is seasonal addition to the melting glaciers and strengthens the Indus river flow that irrigates the bread basket (Indus plains) of Pakistan. According Archer and Fowler [6] in Himalayas Karakoram Kindukush (HKH) the forecast of summer flow in rivers like Indus is also related to the amount of winter precipitation. Therefore, precipitation variability and its forecast not only in winter but also in subsequent spring is instrumental for agriculture based on irrigation in the Indus plains as well as in the areas of rain fed grain crops and especially in the northern and northwestern fruit growing regions where WSP contribute substantially.

Pakistan has four patterns of precipitation, Indian Summer Monsoon (ISM), the western disturbances (WDs) system in winter, a cyclonic system from Arabian Sea and local thunderstorms based on convective activity [7]. Amongst these, the first two are regular atmospheric systems in summer and winter respectively with promising precipitation while the last two are occasional and unreliable sources of precipitation with local effects. Pakistan generally and its northwestern parts particularly receive precipitation as surface influence of subtropical westerlies called WDs prevail in winter and spring (WS). The WDs are defined as closed cyclonic circulation at sea level associated with eastward moving upper air trough in the subtropical westerlies flow [8] [9]. The southward migration of midlatitude westerlies in winter of the northern hemisphere brings the major part of the subcontinent under its influence and disrupts the normal atmospheric circulation [10]-[13]. The WDs are usually nurtured by the depression over the Mediterranean region that brings precipitation to central southwest Asia (CSWA) and surrounding region from December to March [14]. The interaction between lower trophospheric flow and mountains encourages the cyclogenesis [15] that is why the western and northern mountainous parts of Pakistan receive considerable amount of precipitation in winter and early spring.

El Niño/Southern Oscillation (ENSO) is the most widely investigated coupled ocean-atmospheric phenomenon due to its world wide repercussions on climate particularly on precipitation. The Khan [16] claims that the interannual mode of SST anomalies in Arabian Sea and other parts of northern Indian Ocean follow periodicity more or less on ENSO time scale. The Krishna Kumar et al. [17] argue that El Niño is the major driver behind droughts in subcontinent and they [18] also highlighted that central Pacific Ocean based El Niño have strong negative impact on Indian summer monsoon (ISM) while eastern Pacific based El Niño have less impact on ISM comparatively. In this context, the time period of El Niño (La Niña) evolution also matters a lot. However, the ISM-ENSO relation has been subjected to variation in the $20^{\text {th }}$ Century [19].

The ENSO driven sea surface temperature anomalies (SSTA) trigger the atmospheric circulation that distract the midlatitude storm track and influence the winter in the northern hemisphere [20]. The North Atlantic Oscillation (NAO) has profound repercussions on global climate and numerous studies report the influence of NAO on the remote precipitation of northern hemisphere [21] [22]. The NAO Index (NAOI) shows dominant positive phase in the last three decades [23] and has induced precipitation anomalies in the subtropical regions, Eastern Europe and across Asia [24] [25]. Pakistan is located on the eastern border of WDs system which is embedded in the westerlies flow and therefore, the precipitation anomalies in Pakistan during the winter spring (WS) period can not be isolated from the influence of NAO and ENSO.

We can fathom the significance of WSP by three parameters. First, the uneven distribution and insufficient annual amount of precipitation in Pakistan increases the importance of short term forecast. Second, the summer monsoon is the primary source of rainfall in Pakistan, its short duration and highly variable nature increases the importance of WSP as a secondary source of precipitation for life and agriculture. Third, the study of intraseasonal and inter-seasonal variability of precipitation is highly pertinent for successful forecast [26]. The summer and winter precipitation in Pakistan has remained under discussion, but least attention has been paid to WSP. Three months intraseasonal WS is defined by February-March-April (FMA). In this, paper for the first time we examined WSP in Pakistan over the period from 1961-2006. We have tried to seek out the relation of WSP index with atmospheric circulations and global sea surface temperature anomalies (SSTA) by making use of EOF as diagnostic tool, and locate potential predictors.

\section{Data and Methods}

We use the FMA mean monthly ground observed data of 26 stations (Figure 1(b)) obtained from Pakistan Me- 
teorological Department (PMD) Government of Pakistan over the period of 1961-2006. The second dataset consists of reanalysis [27] of National Centers for Environmental Prediction/National Center for Atmospheric Research (NCEP/NCAR) comprised of sea level pressure (SLP), 500 hPa geopotential field and $200 \mathrm{hPa}$ zonal wind with spatial resolution of 2.5 latitudes $\times 2.5$ longitudes. The third dataset consists of long term mean monthly NOAA extended reconstructed surface temperatures (ERSST.v3) [28]) with grid resolution of 2.0 degree latitude $\times 2.0$ degree longitude. The Physical map (Figure 1(a)) has been prepared in ArcGIS to show the detail and geographical distribution of landforms that affect the spatial distribution of WSP in Pakistan due to their thermodynamic impact on moisture containing winds.

The major steps of the analysis are given as follow.

1) Time series are constructed based on regional and national averaged precipitation and their variance in order to know the spatial-temporal characteristics of WSP in Pakistan.

2) EOF was performed using ground observed data of WSP in order to obtain the spatial distribution of coefficient (spatial pattern), time amplitude (time series) and captured percentage of variance in the study domain over the study period.

3) The most important step was to measure correlation between EOFs and responding atmospheric circulations at different geopotential heights.

4) Time-lag technique was applied to fathom the relation between EOF and global SST anomalies.

5) Eventually appropriate predictors have been located.

\section{Characteristics of WSP in Pakistan}

Based on observations Figure 2(a) depicts annual cycle of regional precipitation based on average monthly precipitation over the period of 1961-2006 and highlights two main wet seasons in Pakistan. It shows that summer monsoon period is the largest source of precipitation and winter-spring precipitation (WSP) is the second largest source of precipitation in the country. The summer monsoon precipitation has been discussed thoroughly but WSP is not given due attention so far. Therefore, this paper is focused on WSP.

The regional distribution of WSP is such that northern and northwestern parts of Pakistan including GB-AK, KP-TA and northern Punjab receive the larger amount while southern Pakistan including Balochistan and Sindh obtain small amount (Figure 3). The characteristics of summer precipitation were entirely different from WSP (Figure 2(a)). In southern Pakistan, the precipitation received in Balochistan was more than Sindh in WS and on the contrary, Sindh gets precipitation more than Balochistan in summer. In WS, the KP-TA obtains more precipitation than Punjab, while in summer wet season Punjab gets larger precipitation than GB-AK and KP-TA. In WSP, KP-TA has larger variance followed by GB-AK, Punjab, Balochistan and Sindh. The hierarchy of regional variance follows the same hierarchy as found in case of regional average WSP (Figure 2(b)). In addition, the summer precipitation seems more complex than WSP in term of deviation from the normal at regional scale.

Figure 3 configures each month spatial distribution of precipitation in WS period where the month of March seems the wettest month. The axis of maximum precipitation that extends from "Peshawar valley through Hazara Division and Punjab up to Azad Kashmir" (PVAK axis) mark this area favorite for precipitation due to its geographical location and orographic factor. From west to east along this axis as well as north to south across this axis precipitation amount decreases. The $20 \mathrm{~mm}$ isohyets mark the outer apparent limits at north and south of maximum precipitation concentration area; this area stretches over northwestern rugged parts of the country. The impact of landforms is discernible on spatial distribution of precipitation and gives an impression that rugged topography triggers the precipitation in the WS period that is why scantiness of WSP is not uncommon in plains of Pakistan.

The time series in Figure 4(a) expresses Pakistan WSP index which is evident of interannual and interdecadal variability. The highest range of interannual variability occurs in the mid-1960s, mid-1980s and by the turn of the century. The 9-year averaged curve demonstrates that change of phase occurs from above to below normal precipitation in the 1970s, from below to above normal in the 1980s and continues up to the mid-1990s, this phase is the longest amongst all interdecadal episodes of precipitation change in the study period. In the late 1990s, the precipitation shifts again from above to below normal and continues onward up to the end of the analysis period. Figure 4(b) indicates time series of WSP at regional scale that shows obvious interannual variability and acknowledges that Sindh has the smallest while KP-TA has the largest amount of average precipitation followed by GB-AK, Punjab and Balochistan; the same regional setup of WSP is also supported by annual cycle based on monthly averaged precipitation in Figure 2(a). 


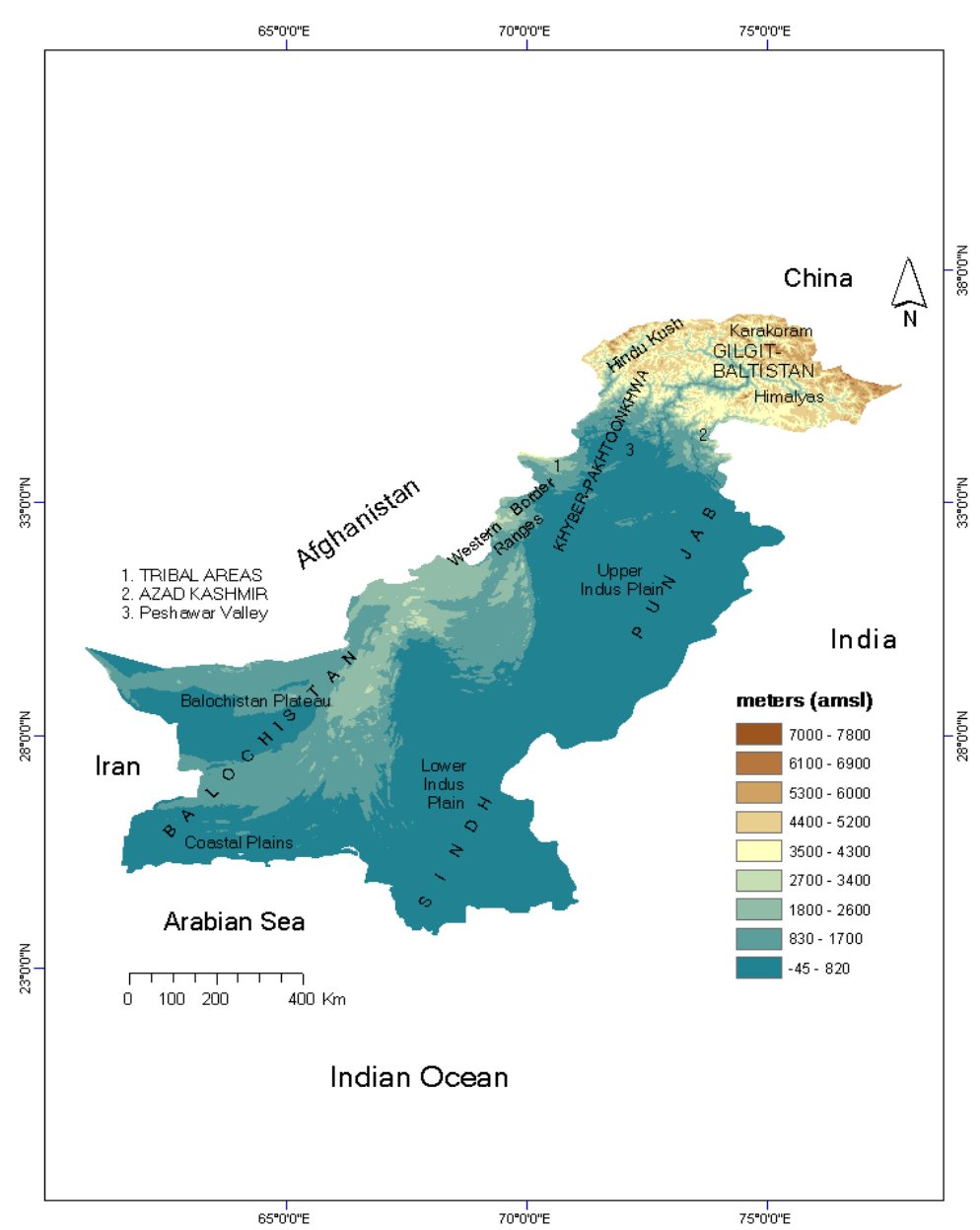

(a)

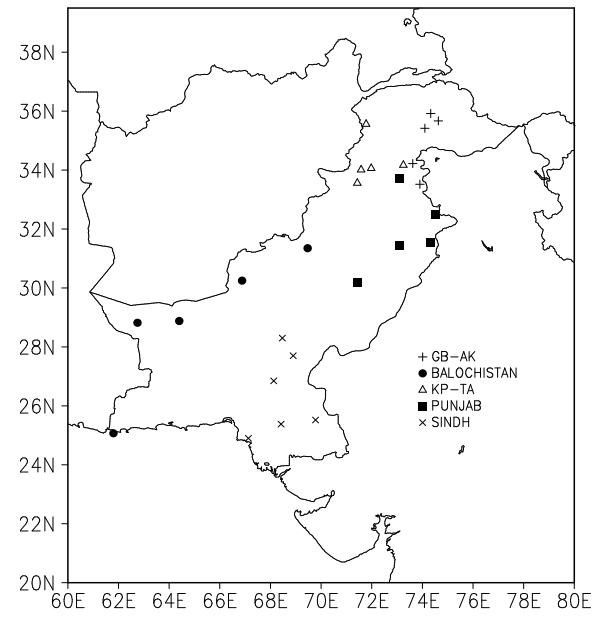

(b)

Figure 1. (a) Physical map shows landforms detail of the study area; (b) Geographical distribution of meteorological stations. Stations with the same symbols mark a schematic division of the study area with the following detail which is helpful in discussion at sub regional level. (i) Gilgit-Baltistan and Azad Kashmir (GB-AK); the northern parts of Pakistan comprised of lofty mountains. (ii) Balochistan; the southwestern parts of Pakistan. (iii) Khyber-Phakhtoonkhwa and Tribal Areas (KP-TA); the northwestern parts of Pakistan. (iv) Punjab; mainly consists of upper Indus plain and Potwar Plateau. (v) Sindh; the southeastern parts of Pakistan mainly consists of lower Indus plain. 


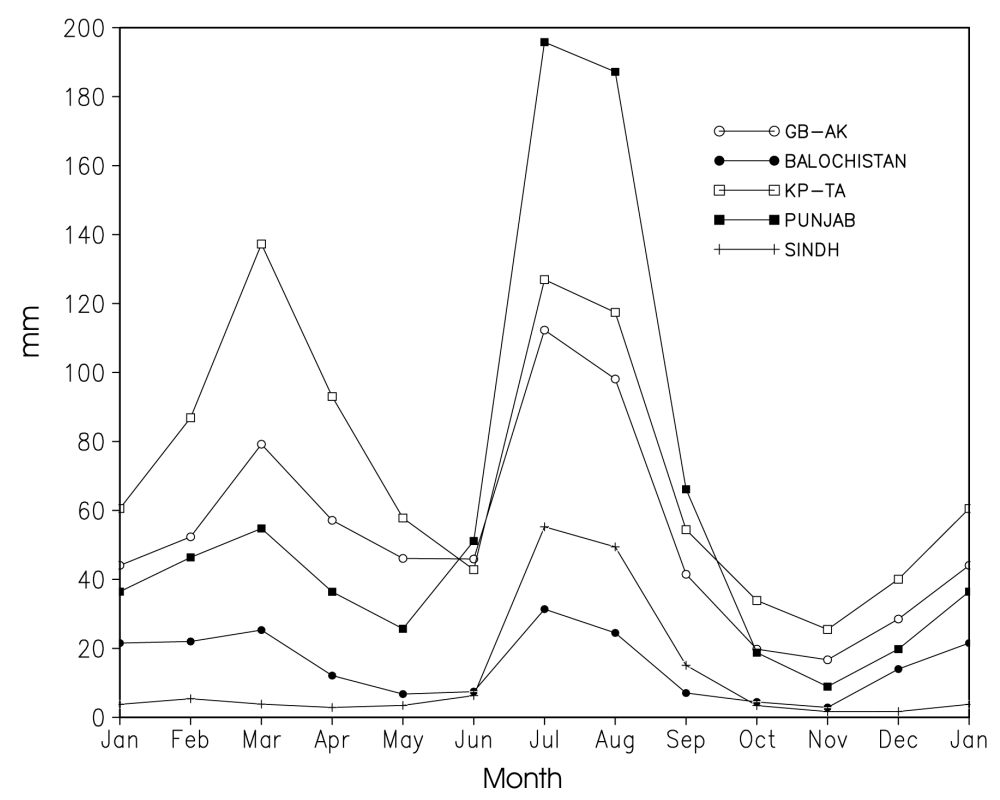

(a)

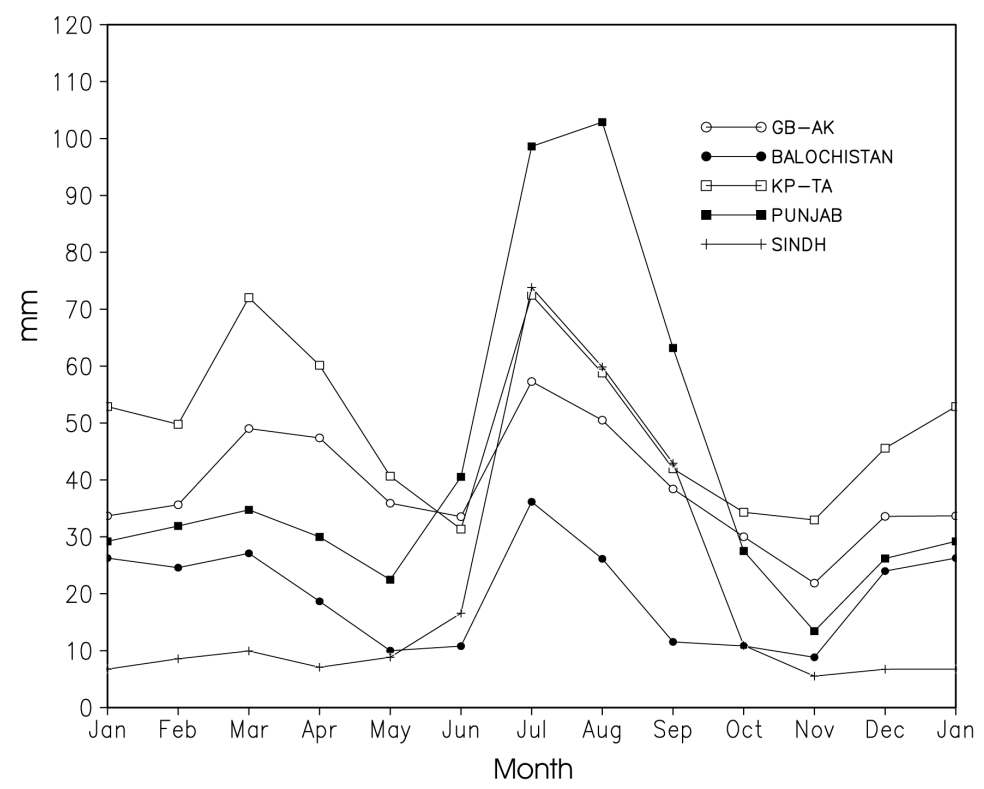

(b)

Figure 2. Average annual cycle of precipitation (a) and standard deviation (b) of regional precipitation over the period of 1961-2006.

Consistency between regional and national WSP is the salient feature where each regional and national time series are found consistent above 0.01 significance level. Hence, responding to GB-AK, KP-TA and Punjab Pakistan shows highest Rc values equal to $0.92,0.91$ and 0.91 respectively and in response to Balochistan and Sindh national WSP shows comparatively low correlation values equal to 0.69 and 0.47 respectively. It is to be noted that the GB-AK, KP-TA and Punjab are the regions which share PVAK axis, the area of maximum precipitation concentration in WS period (see Figure 3).

\section{Observed Average Atmospheric Condition during the Study Period}

Keeping in view the average atmospheric circulation in FMA, the Panel 5a depicts Siberian high and low over 


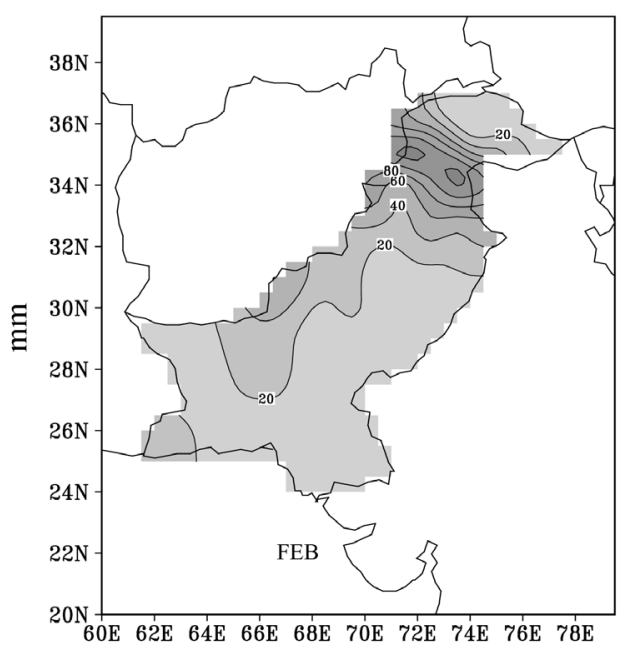

(a)

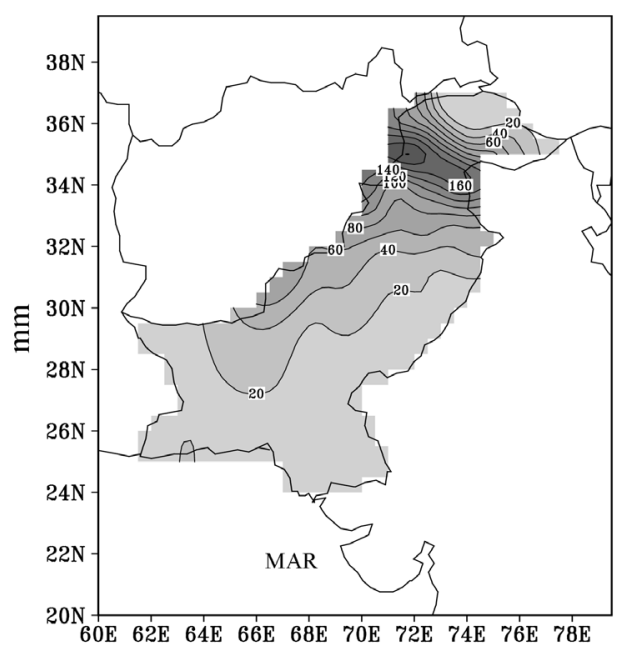

(b)

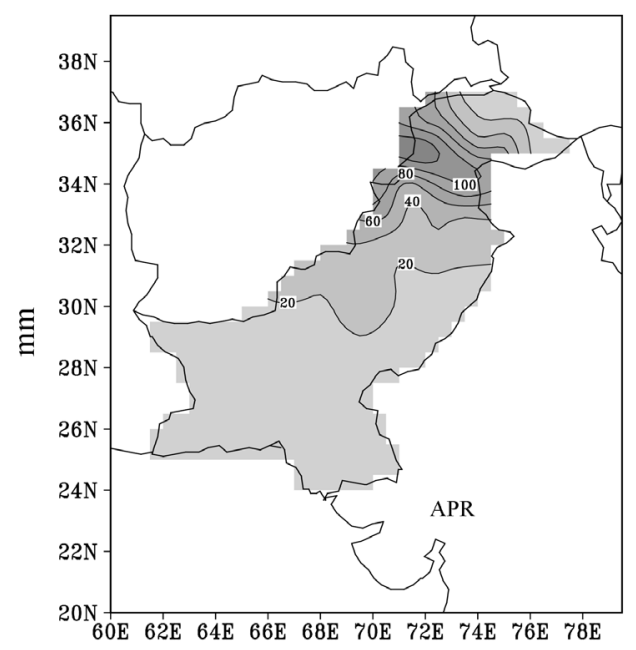

(c)

Figure 3. Spatial distribution of average precipitation in the study period.

India. The Icelandic low and Azores high support the existence of NAO. The Aleutian low and extensive high pressure in the Pacific subtropical basin hold up the north Pacific Oscillation (NPO). The $500 \mathrm{hPa}$ field (Panel 5b) supports trough over Middle East as well as over East Asia and ridge over Central and South Asia including Pakistan. The $200 \mathrm{hPa}$ vector wind (Panel 5c) acknowledges that the belt of westerly was centered over $30^{\circ} \mathrm{N}$ latitude where Middle East westerly jet is over Mediterranean region and Middle East; simultaneously East Asian Jet (EAJ) seems very strong over East Asia. The strength of westerly jet over western Asia and WDs in Pakistan are closely associated. The enhanced Middle East Westerly Jet (MEWJ) results into intensified WDs of the study region. The intensification of WDs over CSWA encourages the moisture flux from Arabian Sea eventually increases precipitation in Pakistan [29].

\section{Principal Mode EOF-1}

The leading EOF mode captures $63.4 \%$ variance and the EOF-2 contributes $11.1 \%$ the total variance. The two EOF modes together contribute $74.5 \%$ of the total variance therefore are capable to characterize the winterspring precipitation variability in Pakistan over the period of 1961-2006.

\subsection{Leading Mode with Positive Consistent Pattern}

The EOF-1 (Figure 6(a)) reflects consistent positive spatial coefficient pattern throughout the country. The node 


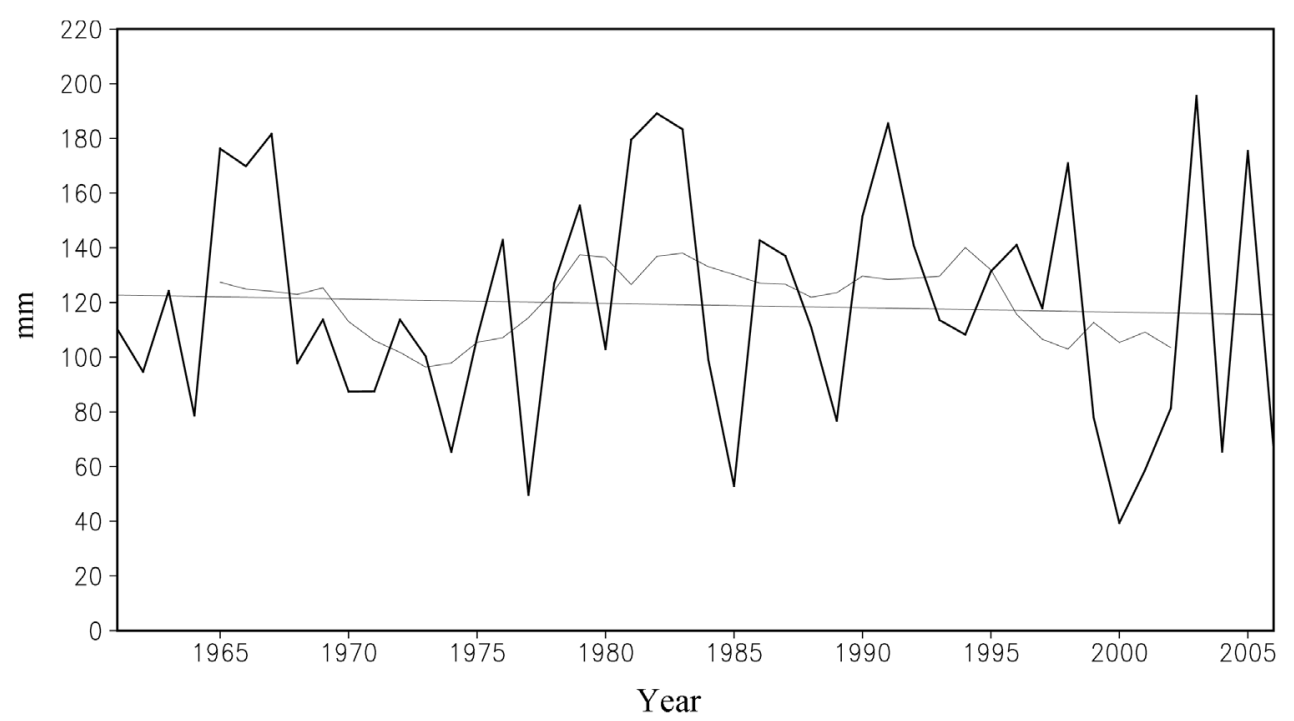

(a)

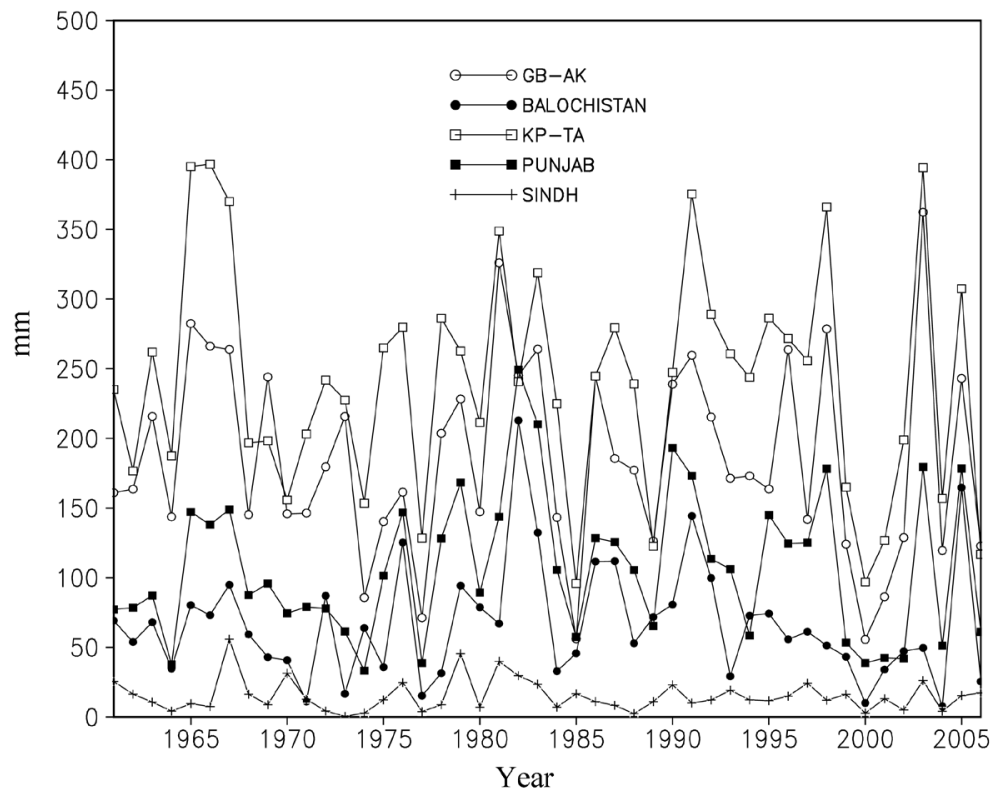

(b)

Figure 4. WSP in Pakistan over the study period: (a) Spiky line denotes seasonal (FMA) averaged precipitation that reflects interannual variability and curved line reflects 9-year running average; (b) Regional time series, spiky lines denotes regional averaged WSP characterized by obvious interannual variability.

of maximum variability of WSP is anchored over the PVAK axis, Quetta region is moderately responding while southern part of the country has less apparent response. Therefore, this pattern can be termed as single-pole pattern. Its time series (EOF-T1) is variable at interannual time scale. The years from late 1960s to late 1970s have less precipitation over most of the country and most importantly from 1999-2003 was the obvious dry period in this mode. The mid-1960s, early 1980s and early 1990s were the wet years in this mode. The time series reflect that most of the years are located with in between 1 and -1 and about 20 years in the study period show high variability. The last ten years of the time series have shown high variability. Table 1 is indicative of correlation coefficient between EOF-T1, each regional and national time series of WSP and achieves 0.01 significance level, it also validates EOF-1 is the most appropriate representative mode. The correlation of EOF-T1 and national precipitation index was 0.94 over the study period. 


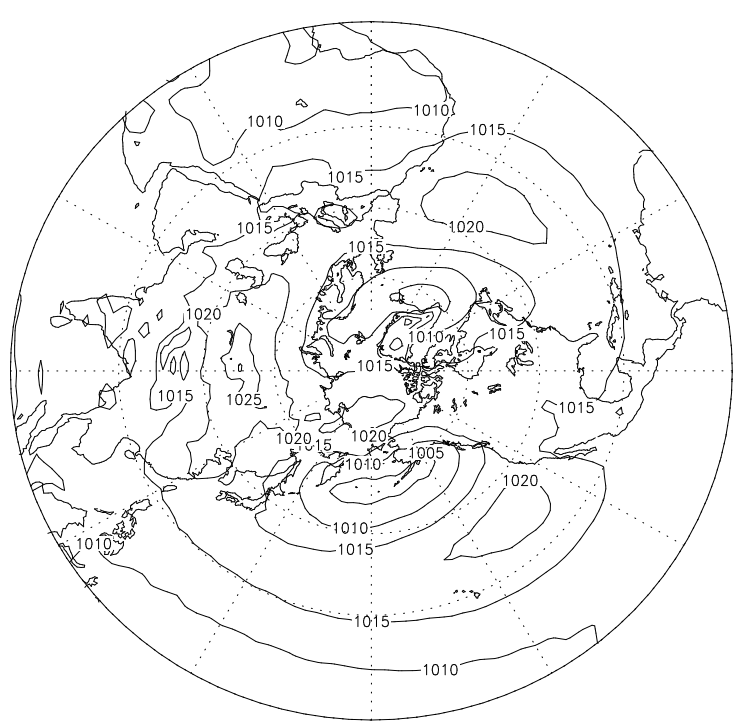

(a)

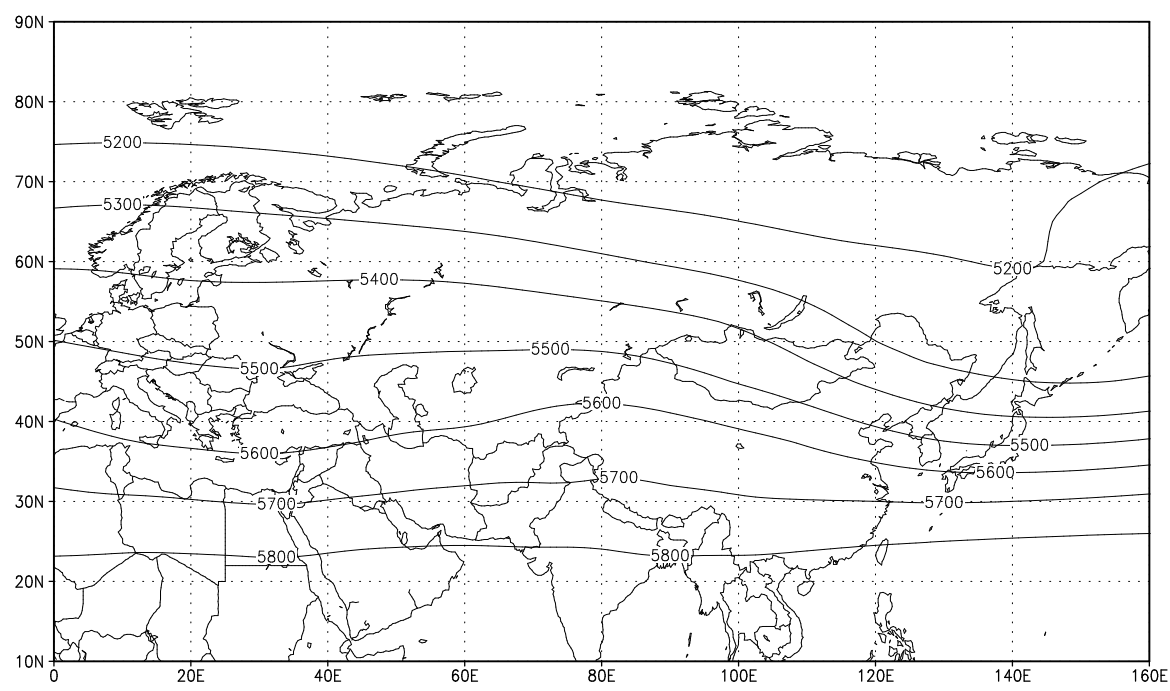

(b)

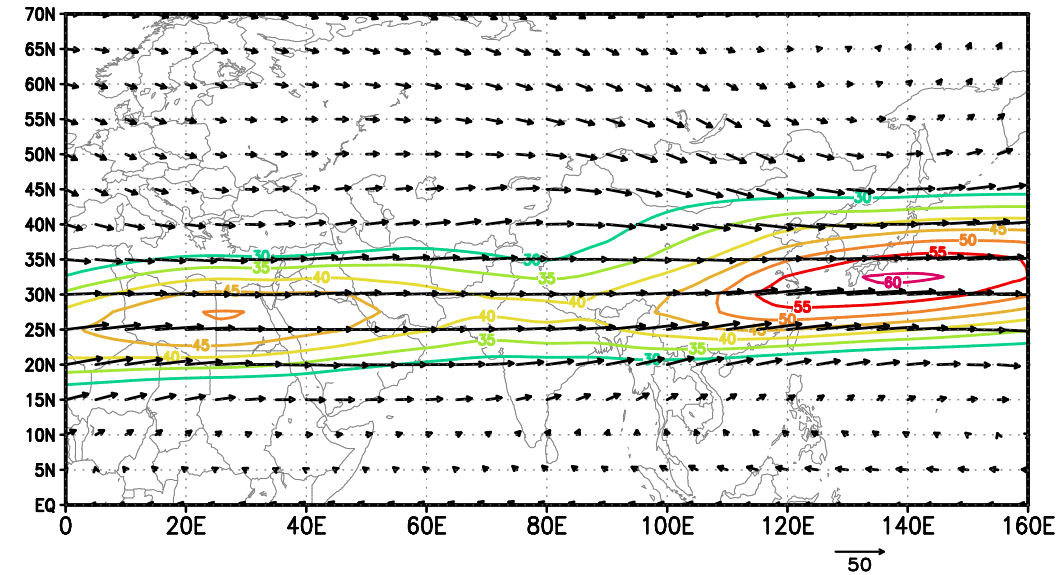

(c)

Figure 5. FMA average atmospheric circulation (a) SLP (unit: hPa); (b) 500 hPa (unit: gpm); (c) 200 $\mathrm{hPa}$ wind vector and velocity (unit: $\mathrm{m} / \mathrm{s}$ ). 


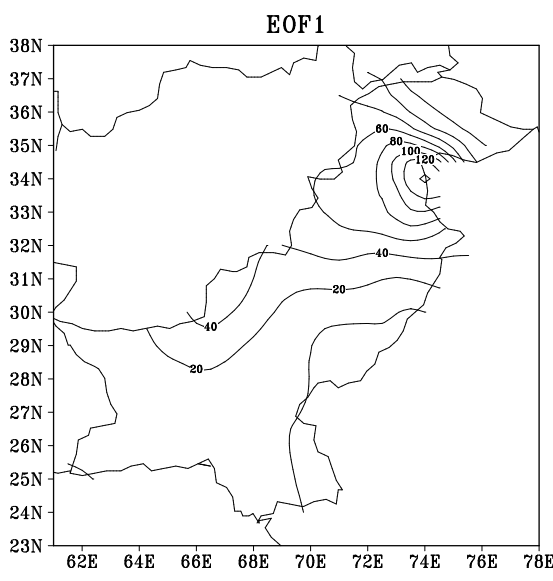

(a)

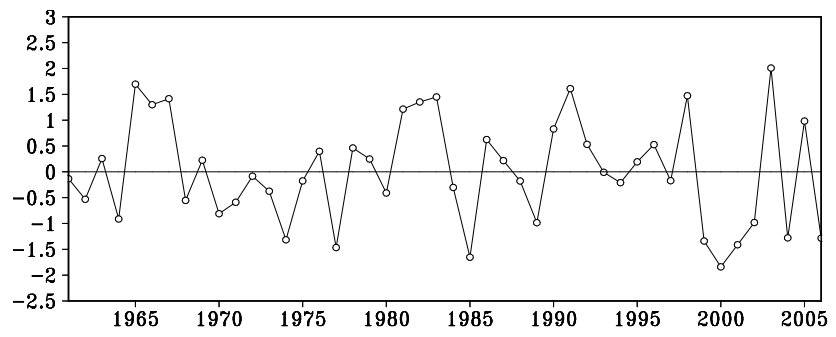

(b)

Figure 6. EOF leading mode winter-spring (FMA) precipitation, 1961-2006: (a) Coefficient spatial distribution indicative of departure from the normal; (b) Time series (variance: 63.4\%).

Table 1. Correlation coefficient between EOF-T1 and time series of regional and national scale winter-spring precipitation over the period of 1961-2006.

\begin{tabular}{ccccccc}
\hline & 1 & 2 & 3 & 4 & 5 & 6 \\
\hline EOF-1 & $0.94^{* *}$ & $0.61^{* *}$ & $0.94^{* *}$ & $0.88^{* *}$ & $0.39^{* *}$ & $0.98^{* *}$ \\
EOF-2 & -0.10 & $0.53^{* *}$ & -0.22 & $0.36^{*}$ & $0.30^{*}$ & 0.09 \\
\hline
\end{tabular}

1: GB-AK; 2: Balochistan; 3: KP-TA; 4: Punjab; 5: Sindh; 6: Pakistan; $\left({ }^{* *} 0.01\right.$ significance level; ${ }^{*} 0.05$ significance level).

\subsection{Second Mode}

The EOF-2 (Figure 7(a)) recognizes triplepole spatial pattern. The northwestern lofty rugged territory including parts of GB-AK/KP-TA, northeastern Punjab and Quetta-Kalat region in northwestern Balochistan are the three node-regions of winter-spring precipitation variability. This tripole pattern has interannual variability with different characteristics as represented by its time series (Figure 7(b)). The years from 1961-1975 experience precipitation variability at interannual scale with positive anomaly in Quetta-Kalat region as well as in northeastern Punjab on the contrary these years have negative anomaly in GB-AK/KP-TA. Amongst these, the years of 1964, 1965, 1966 and 1969 are the driest in northeastern Punjab, while these are wettest years in KP-TA and GB-AK. The years from 1976-1990 (except 1978) show positive anomalies over Quetta-Kalat and northeastern Punjab, the same years experience negative anomalies in winter-spring precipitation in KP-TA and GB-AK. Further, amongst these the years including 1976, 1982 and 1983 are the wettest and driest years with in respective regions. The years from 1991 and onward show variability that is confined with in the values of -1 and +1 , however gives impression of interannual variability with slight increase winter-spring precipitation in KP-TA and GB-AK as well as a slight decrease in northeastern Punjab and Quetta-Kalat region.

Table 1 (second row) shows the correlation coefficient between EOF-T2 and regional time series which validates the EOF-2 importance at regional level. Responding to EOF-T2, the GB-AK and KP-TA were found above 0.01 level of significance with correlation of -0.48 and -0.76 respectively. In this connection, the Punjab and Balochistan areas project correlation coefficient of 0.38 and 0.65 and attain 0.01 significance level, while the correlation coefficient found in case of Sindh is 0.29 at 0.05 significance level. This regional coefficient distribution supports the anomalous condition shown on Figure 5(a) embracing three strong nodes of variability in winter-spring anomalies in northwestern parts of Balochistan, northeastern Punjab and northwestern parts of the country were symbolized by obvious interannual anomalies through out the study period.

\subsection{Leading Mode in Relation to Atmospheric Circulation}

Figure 9 explains distribution of correlation coefficient between single-pole pattern (EOF-1) and responding SLP, $500 \mathrm{hPa}$ height, $200 \mathrm{hPa}$ field and $200 \mathrm{hPa}$ zonal wind. Reference to the leading mode with maximum vari- 
ability over the PVAK axis, Quetta region with moderate response, and southern parts with no or less response to the atmospheric circulation was found as such that the SLP was above normal in the western Pacific and adjoining Indian Ocean, while below normal over central and eastern Pacific basin. This surface anticyclonic and cyclonic condition over the western and eastern pacific basin could be indicative of southern oscillation (SO). It means the EOF-1 mode embracing impact from SO through teleconnection. Furthermore, the positive pressure anomaly over northern Indian Ocean extends to Arabian Sea and southern proximity of Pakistan was more important because the low level moisture containing flow from the ocean will feed the depression associated with WDs in the study region. The correlation $(\mathrm{Rc}=0.56)$ between EOF-T1 and southern oscillation index (SOI) is marked by statistical significance (Figure 8). The high (low) SOI means decrease (increase) in precipitation of

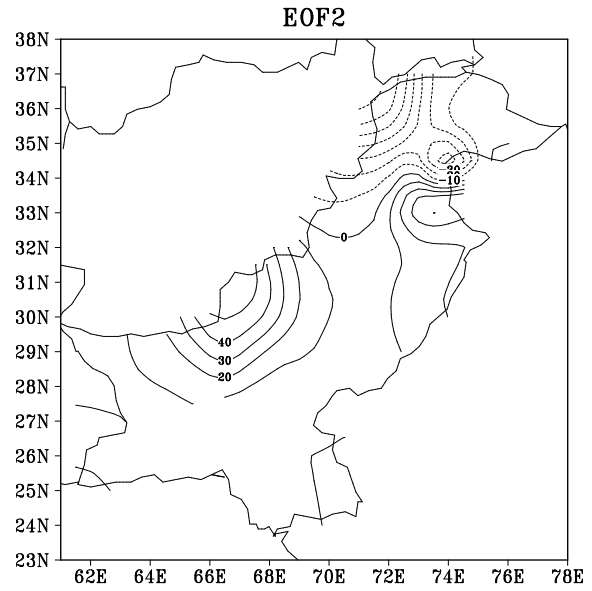

(a)

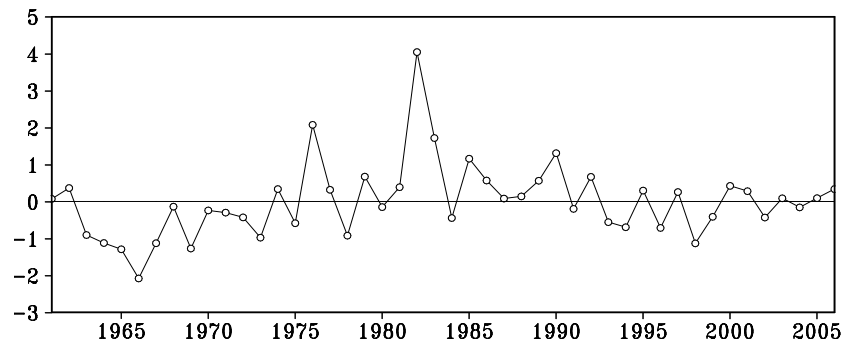

(b)

Figure 7. EOF-2, winter-spring (FMA) precipitation, 1961-2006. (a) Coefficient spatial distribution indicative of departure from the normal; (b) Time series (variance: $11.1 \%$ ).

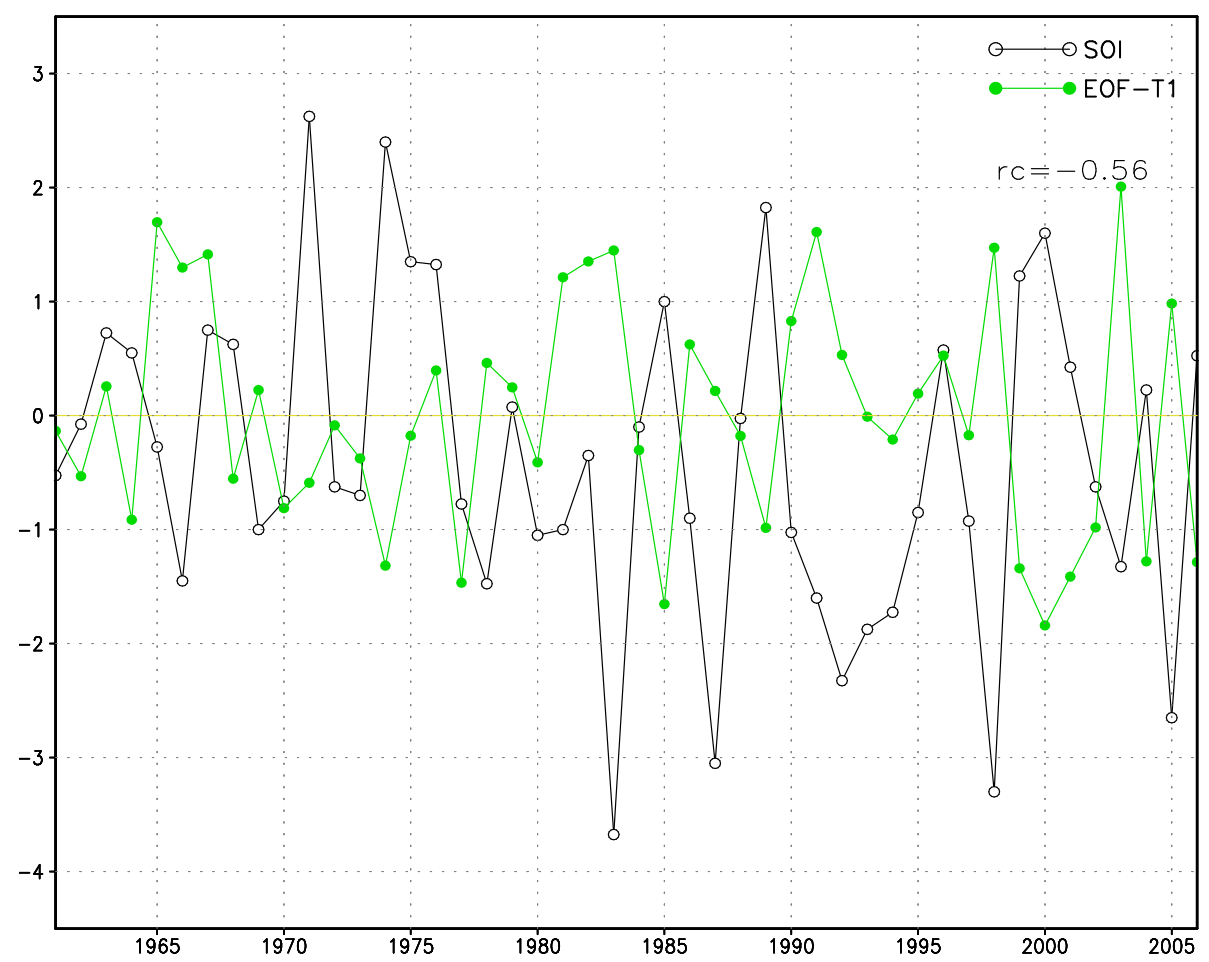

Figure 8. Relation between EOF-T1 and SOI (SOI is the standardized anomaly of the difference in mean SLP measured at Tahiti and Darwin). 


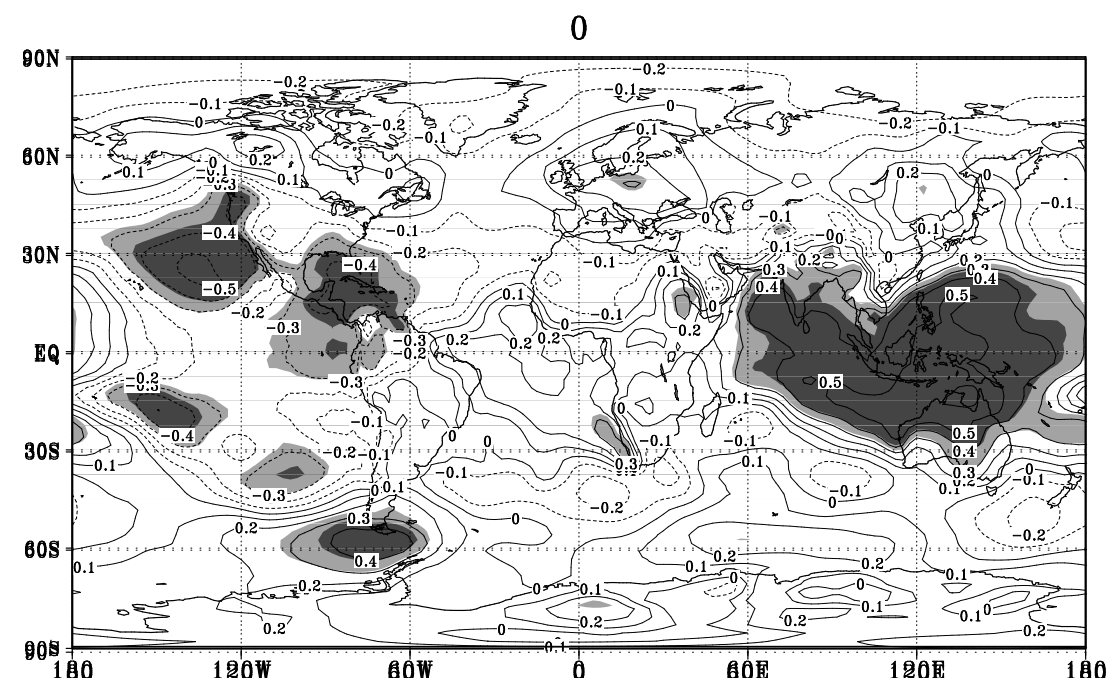

(a)

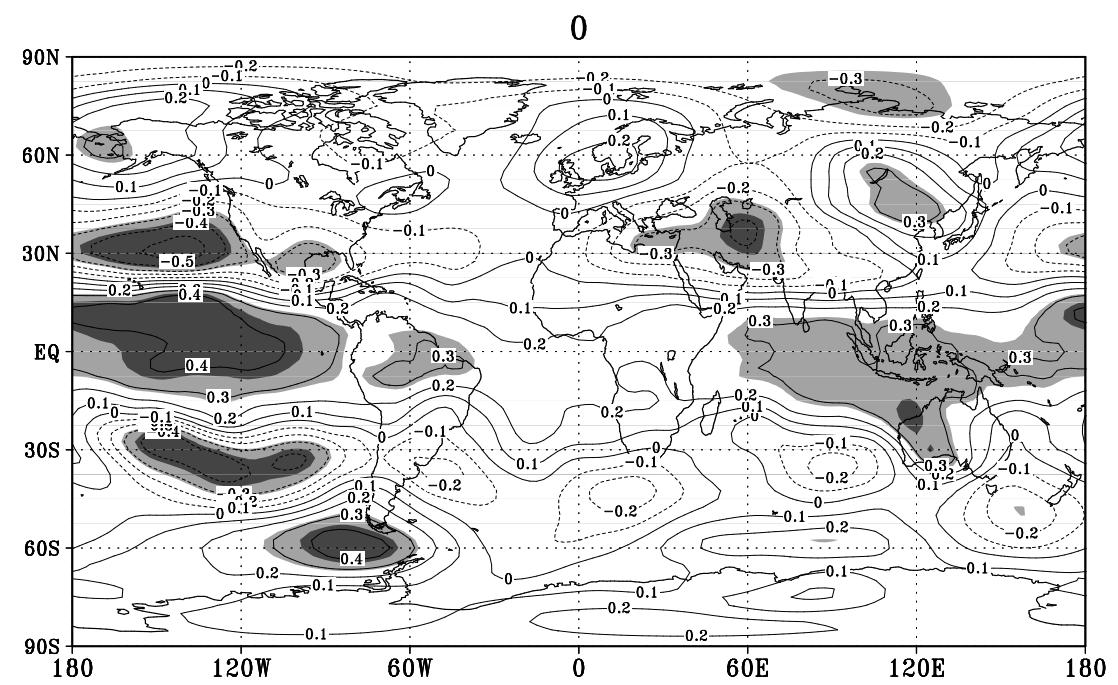

(b)

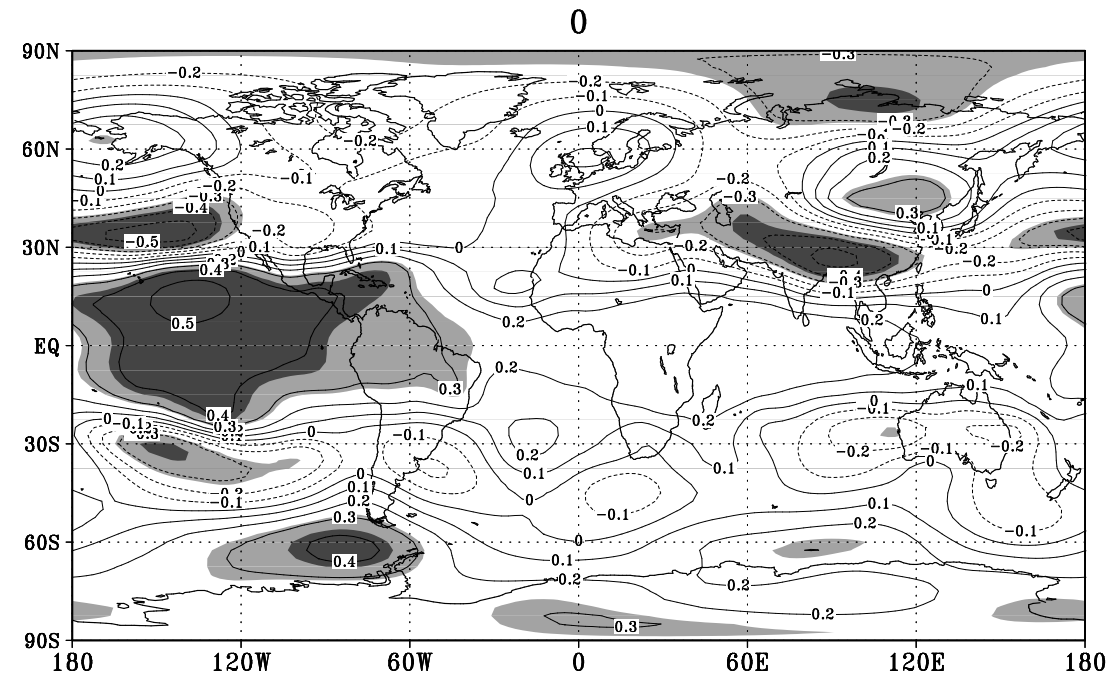

(c) 


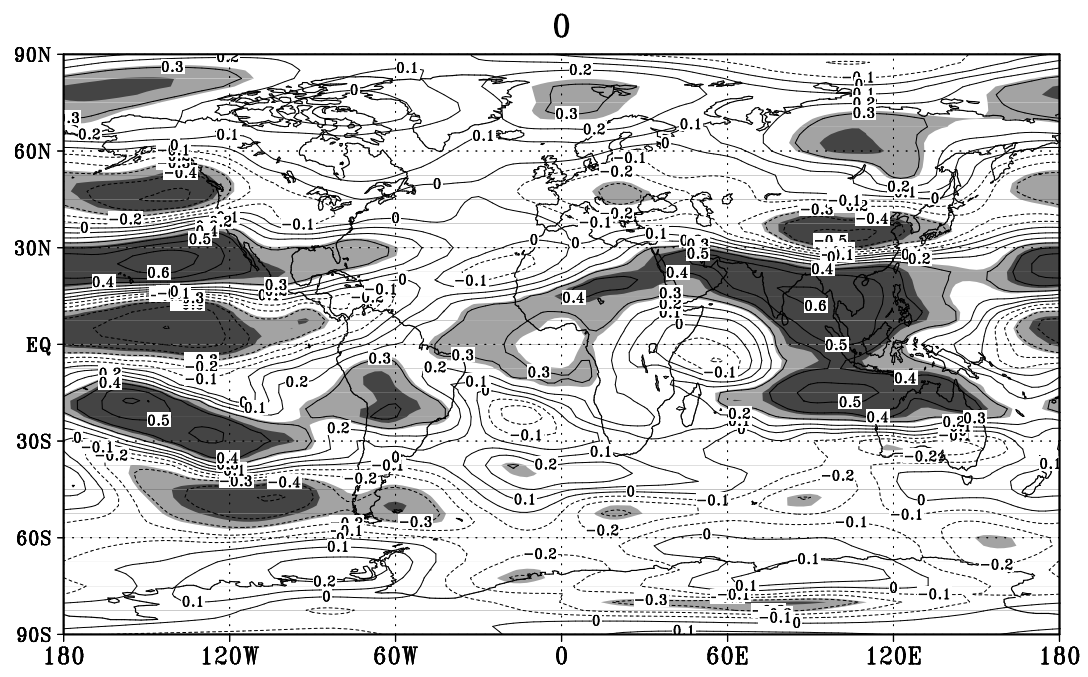

(d)

Figure 9. Correlation coefficient between EOF-T1 and responding (a) SLP; (b) 500 hPa height; (c) 200 hPa height; (d) 200 hPa zonal wind.

the single-pole mode. For example, the index was high from 1999 to 2002 but the precipitation was marked by negative, it is the period of sever drought in Pakistan. This relation is further validated by the Section 5.5, which examines the relation of leading mode with respect to global SST anomalies.

The intensification of the anomalies at $500 \mathrm{hPa}$ over the eastern Pacific basin with positive, negative and positive pattern over tropical, subtropical and mid/higher latitudes respectively ascertains the impact of ENSO positive phase. The surface pressure (Panel 5a) supports the low SO index. Numerous studies like [30] [31] suggest that enhanced jet stream and its eastward shift is very common in winters dominated by El Niño episodes. Reference to $200 \mathrm{hPa}$ zonal wind (Figure 9(d)) the Middle East westerly jet seems strong. If in case, we have no consistency in winter precipitation with interannual variability in the country, in that situation we can expect state of atmosphere with opposite anomalies to those observed in Figure 9.

Responding to the principal mode SLP was above normal in the western Pacific and adjoining Indian Ocean while below normal over central and eastern Pacific basin which establishes relation of anomalous WSP with Southern Oscillation (SO). Furthermore, the positive pressure anomaly over northern Indian Ocean extends to Arabian Sea and southern proximity of Pakistan.

The intensification of the anomalies at $500 \mathrm{hPa}$ over the eastern Pacific basin with positive, negative and positive pattern over tropical, subtropical and mid/higher latitudes respectively ascertained the Pacific/North American (PNA) teleconnection pattern. The strength and east-west shift of East Asian jet stream may determine this sort of pattern. Reference to $200 \mathrm{hPa}$ vector u-wind (Figure 5(c)) the enhanced East Asian jet stream and its eastward shift indicated the positive phase of PNA. The positive mode of PNA pattern is mostly associated with El Niño. Therefore, if the ENSO condition exists it means the chances of positive phase of PNA exist which may enhance the East Asian jet stream and through teleconnection have potential link with the rainfall index in the study domain. The jet core is centered over $30^{\circ} \mathrm{N}$ at $200 \mathrm{hPa}$. A pattern opposite to that found at $500 \mathrm{hPa}$ can be seen with negative, positive, negative pattern over the tropics, subtropics, and higher latitudes of the Pacific Ocean (Panel 5c). This pattern has relationship with central and eastern Pacific patterns. We can deduct that almost all studied tropospheric geopotential levels show that the study region has link with central, eastern and western tropical Pacific Ocean acknowledged by not only atmospheric circulations but also by SSTA (Section 5.4).

\subsection{Leading Mode in Relation to SST Anomalies}

Figure 11 demonstrates time-lag correlation between study area and global SST anomalies in the circumstances when winter-spring precipitation has consistent positive spatial coefficient (EOF-1a) with obvious interannual variability (EOF-T1). Four months prior to FMA the central and eastern equatorial Pacific is warmer this posi- 


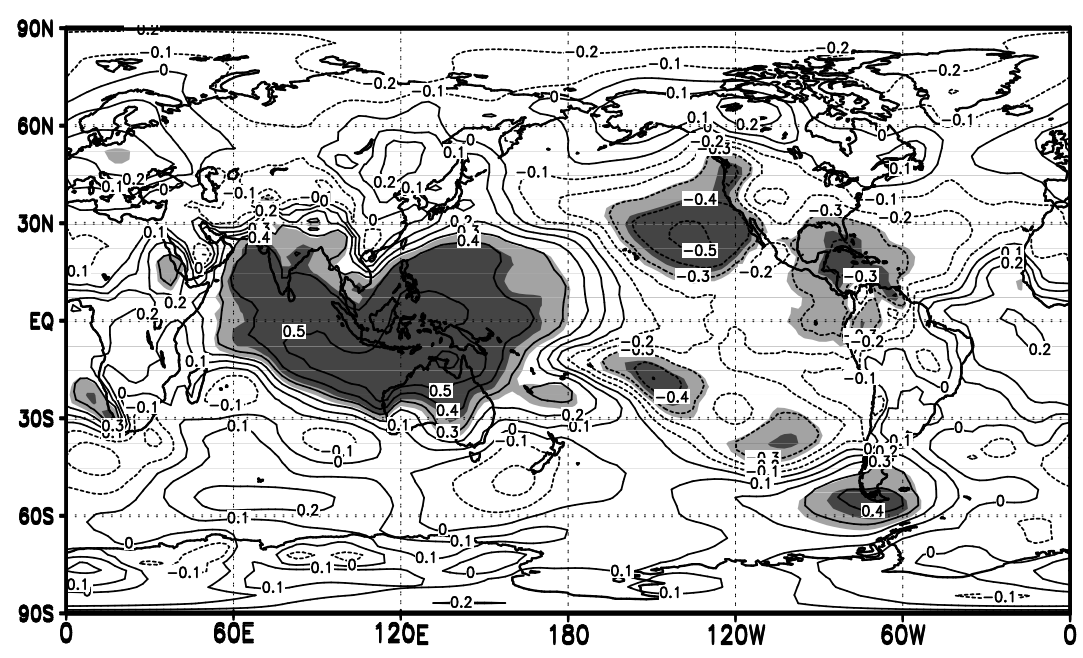

(a)

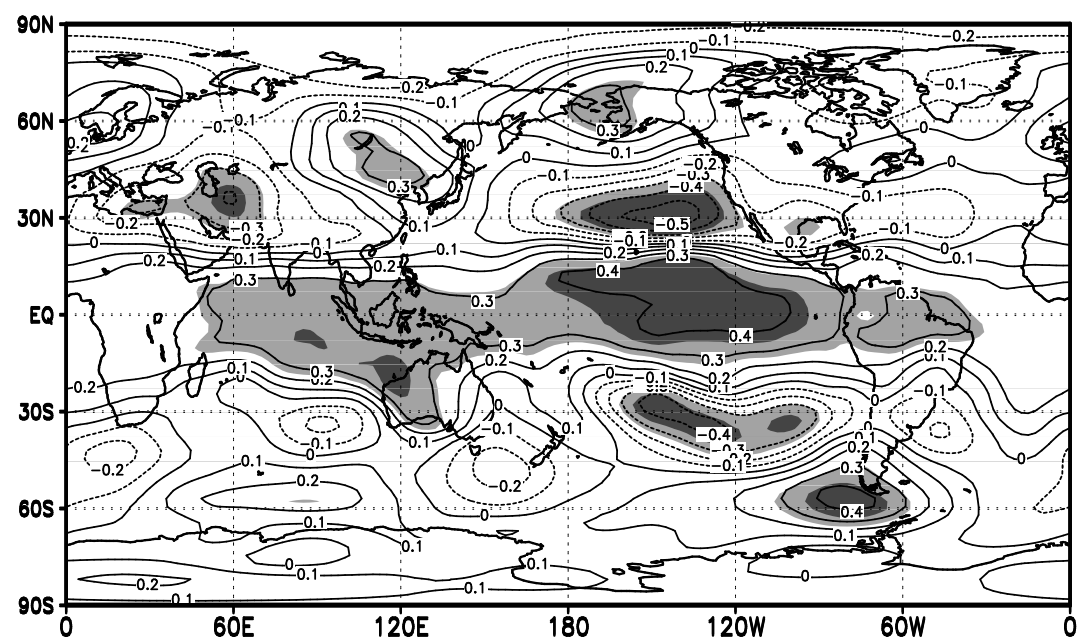

(b)

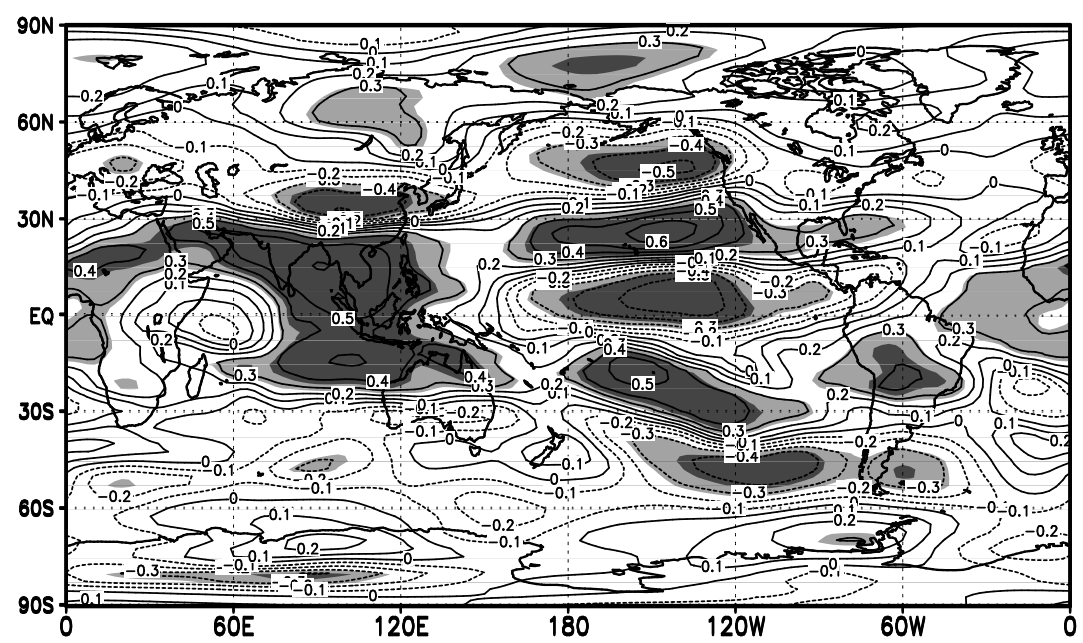

(c)

Figure 10. Correlation coefficient between WSP index and responding atmospheric circulation at (a) SLP (b) $500 \mathrm{hPa}$ (c) $200 \mathrm{hPa}$ zonal wind. 


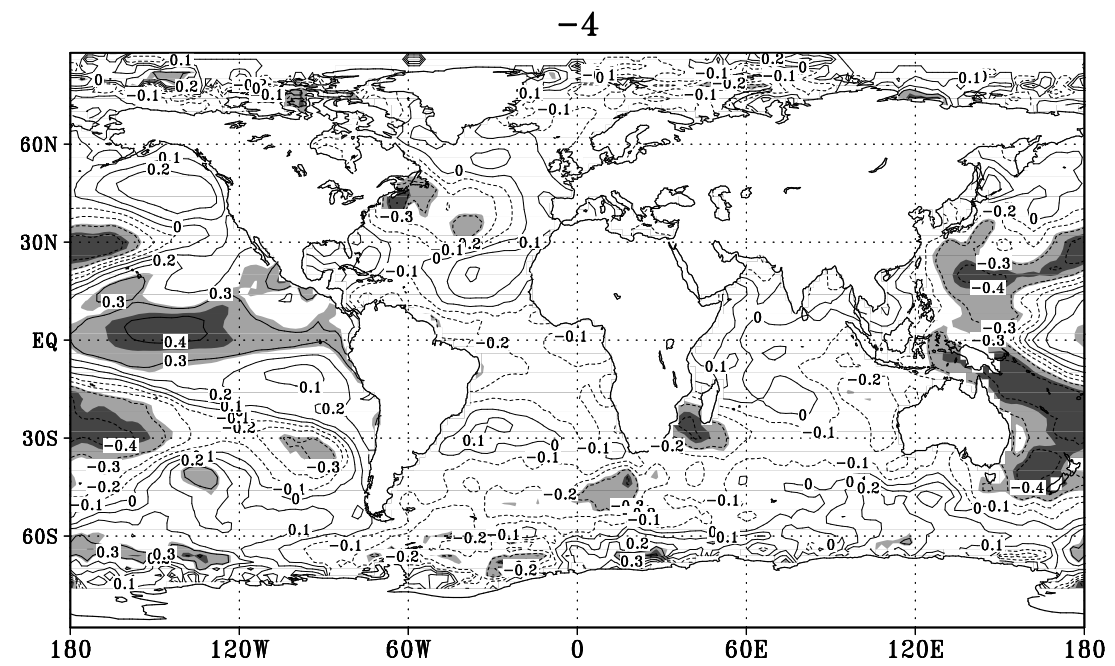

(a)

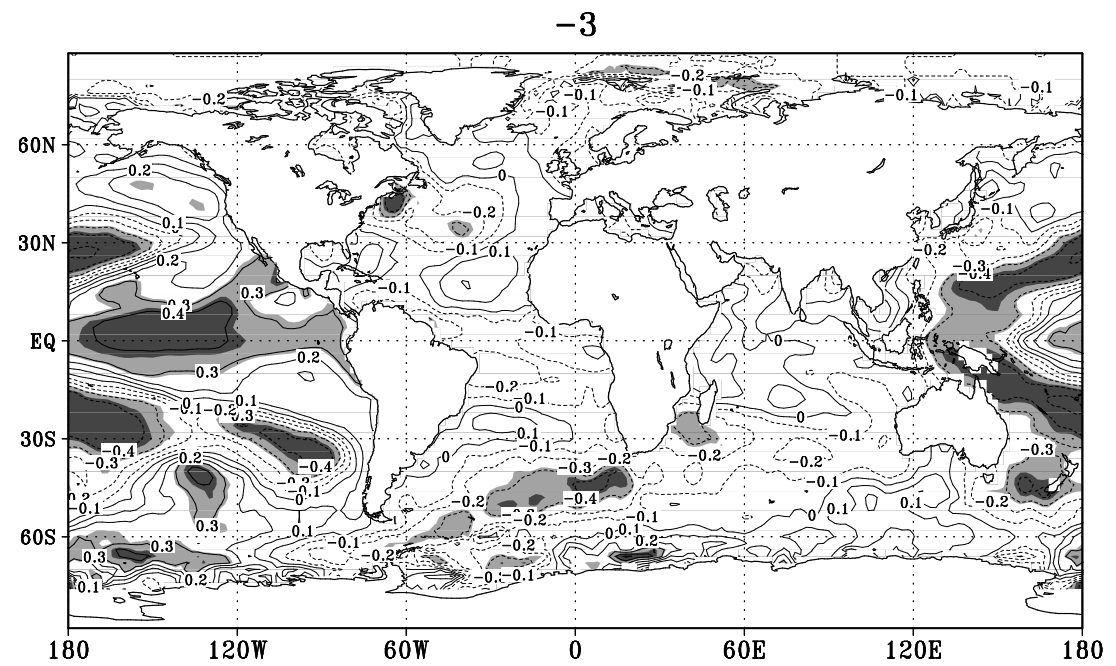

(b)

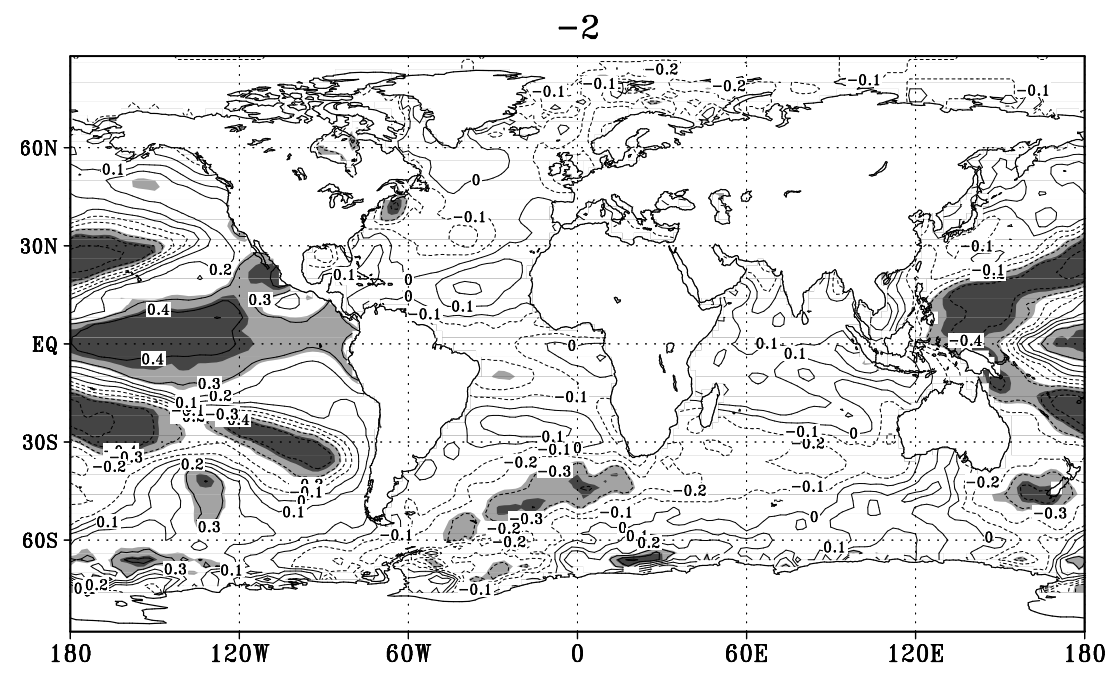

(c) 


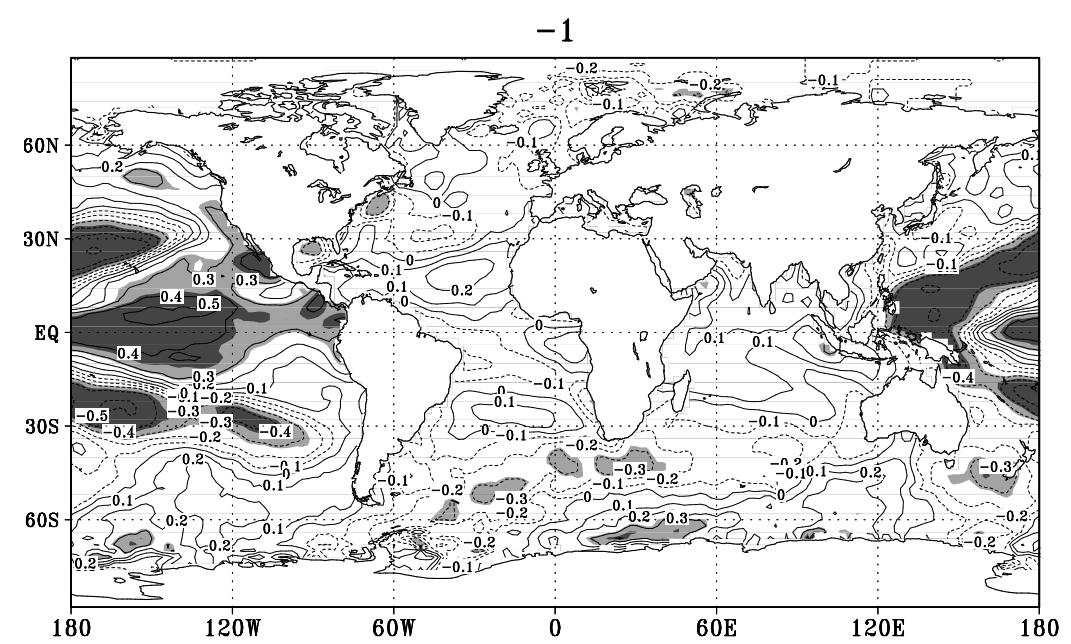

(d)

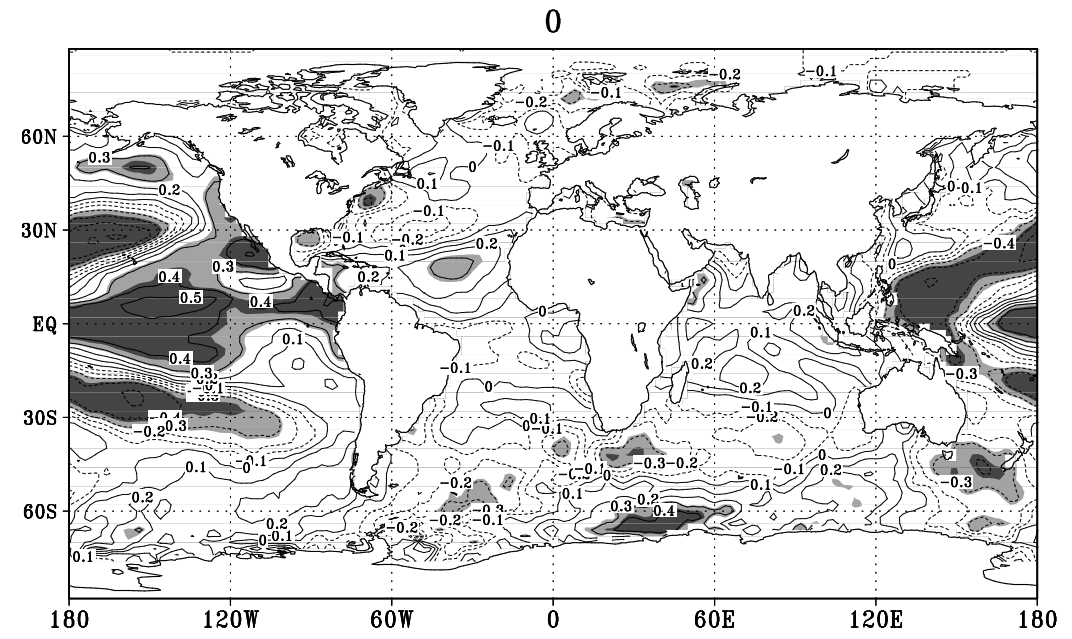

(e)

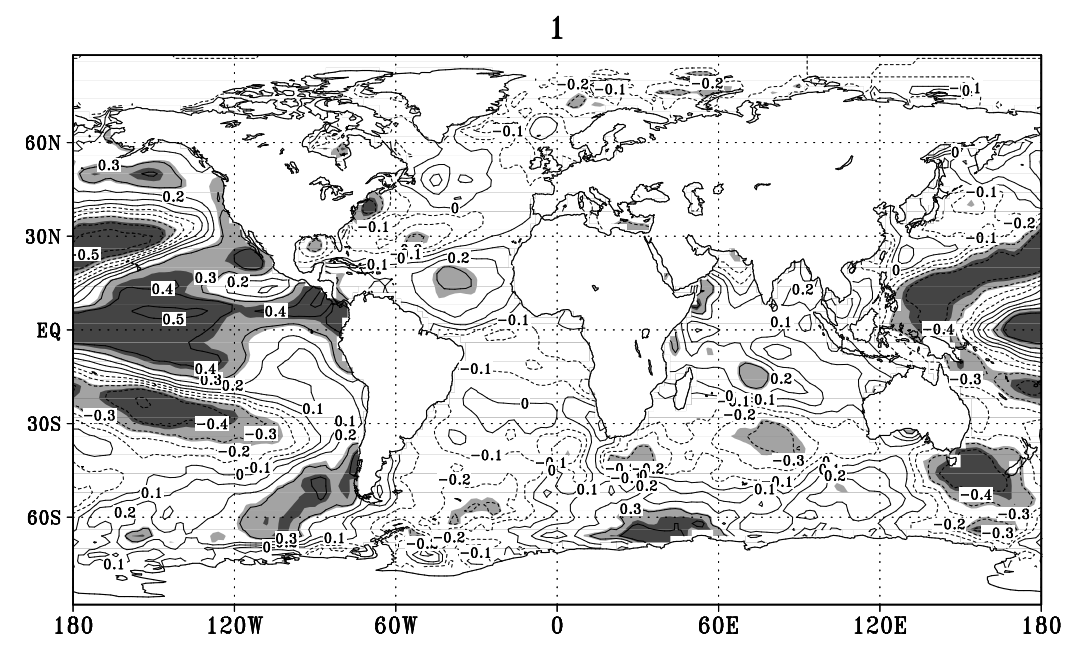

(f)

Figure 11. Time-lag correlation coefficient between EOF-T1 and responding global SST (negative/positive number on top of each panel indicates advance/lag by months) over the period of 1961-2006. 
tive SST anomaly spreads over larger area in a tongue shaped format especially in Niño3.4 regions. The negative SST anomaly extends from western Pacific warm pool region towards subtropical and middle latitudes both at the north and south of the tongue shaped warm SST. In other words, it can be said that areas with negative SST signals are centered over $30^{\circ} \mathrm{N}$ and $30^{\circ} \mathrm{S}$ latitudes with slight extension towards mid-latitudes of the Pacific Ocean in both the hemisphere. The SST anomalies (Panels 11a, 11b, 11c, 11d, 11e and 11f) are found pretty progressive right from "four months" prior case up to the month of March. This situation can be linked to the atmospheric circulation observed in response to the leading mode which signifies that the winter-spring precipitation index is influenced by SO through teleconnection. If in case, we have La Niña condition in post monsoon period and early winter then the chance of negative spatial anomalous pattern of winter-spring precipitation can be expected in Pakistan. For the leading mode Niño3.4 index can be efficiently used as predictor for WSP in Pakistan.

\subsection{Relation between WSP Index and Global SST}

Figure 12 demonstrates time-lag correlation between PC and global SSTA. In four months, prior case (Panel 6a) central and eastern equatorial Pacific SST anomaly is positive and spreads over larger area in a tongue shaped format from the eastern to central tropical Pacific basin. Simultaneously negative SST anomaly extends in two branches, one to each hemisphere from western Pacific warm pool region to the subtropical regions in the Pacific basin, this sort of SSTA in response of WSP seems pretty progressive (Panels 12a, 12b \& 12c). This scenario

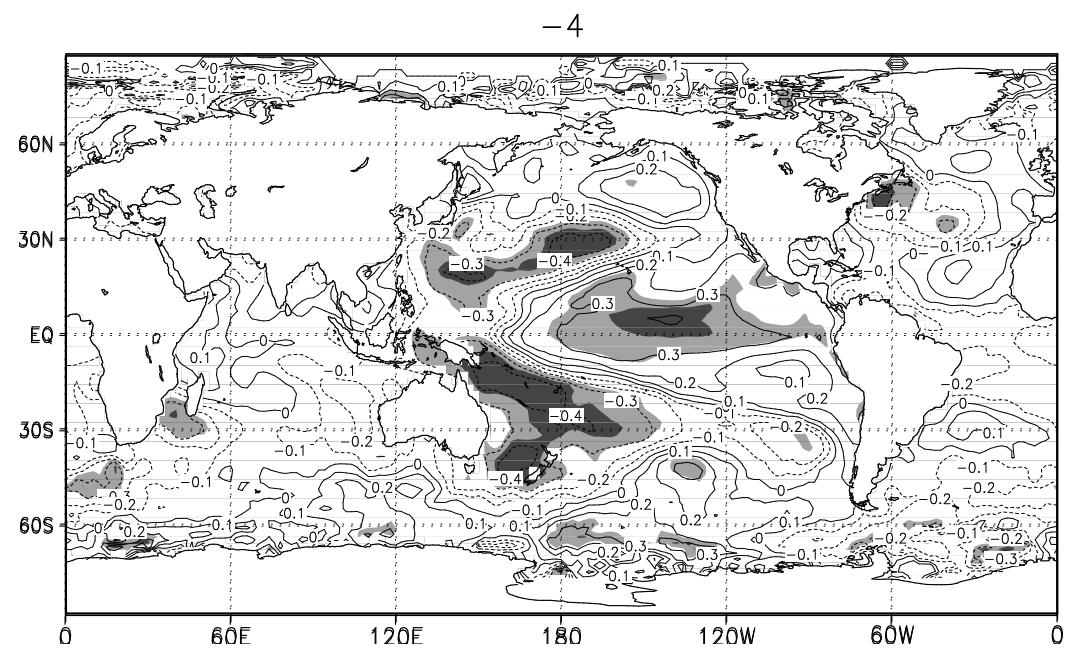

(a)

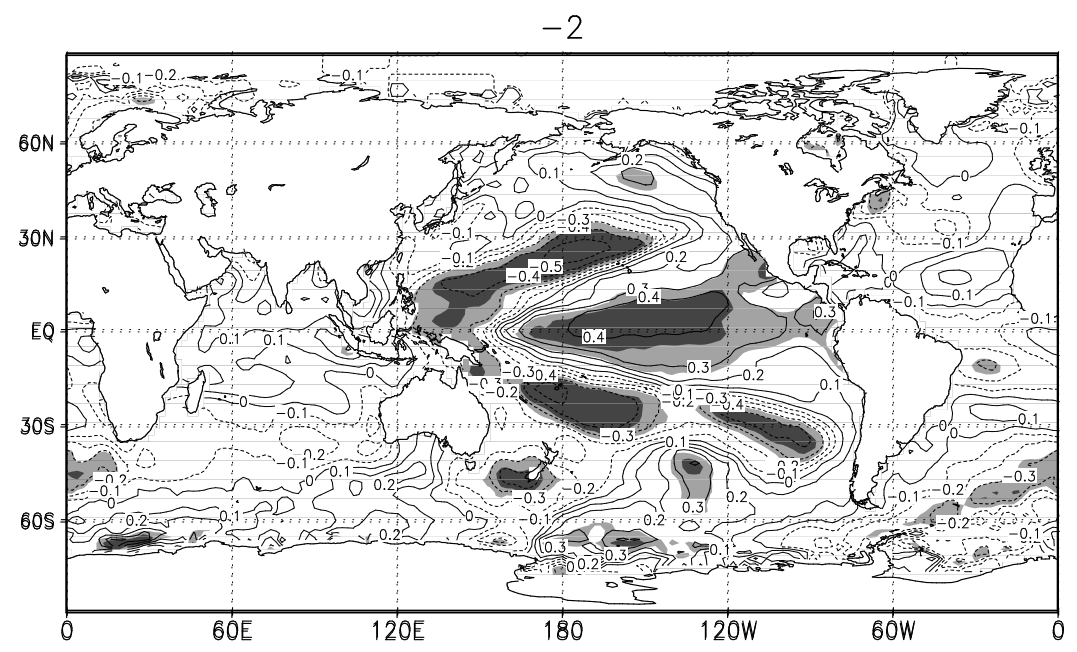

(b) 


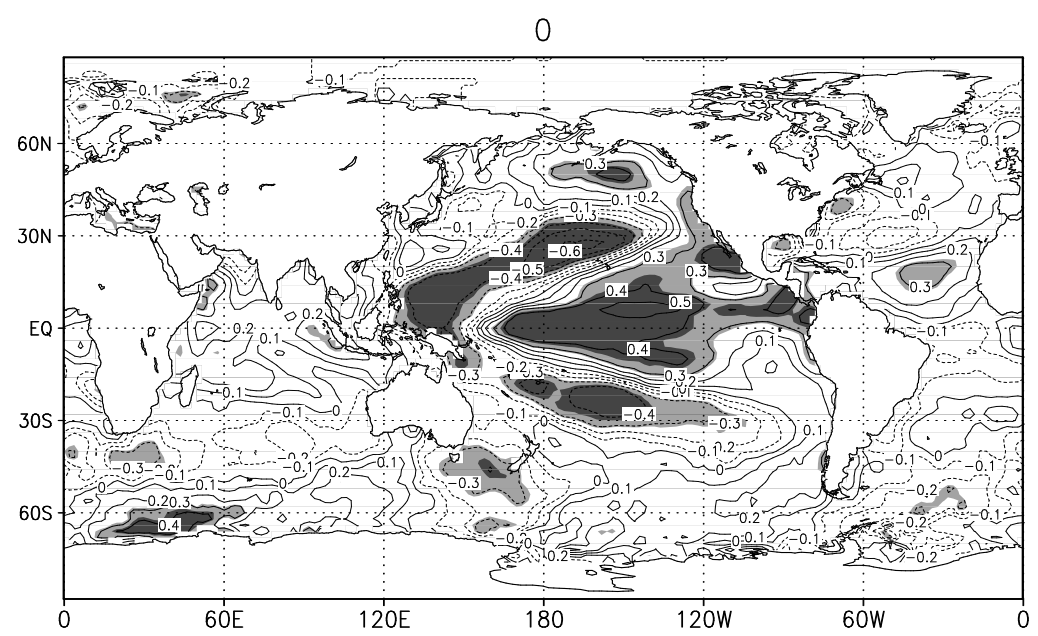

(c)

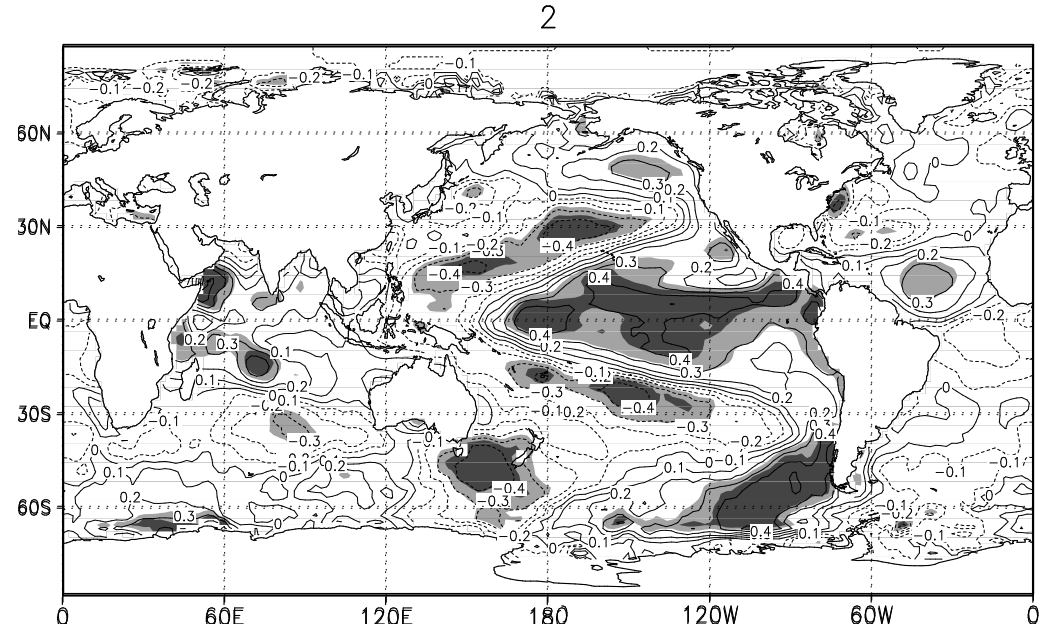

(d)

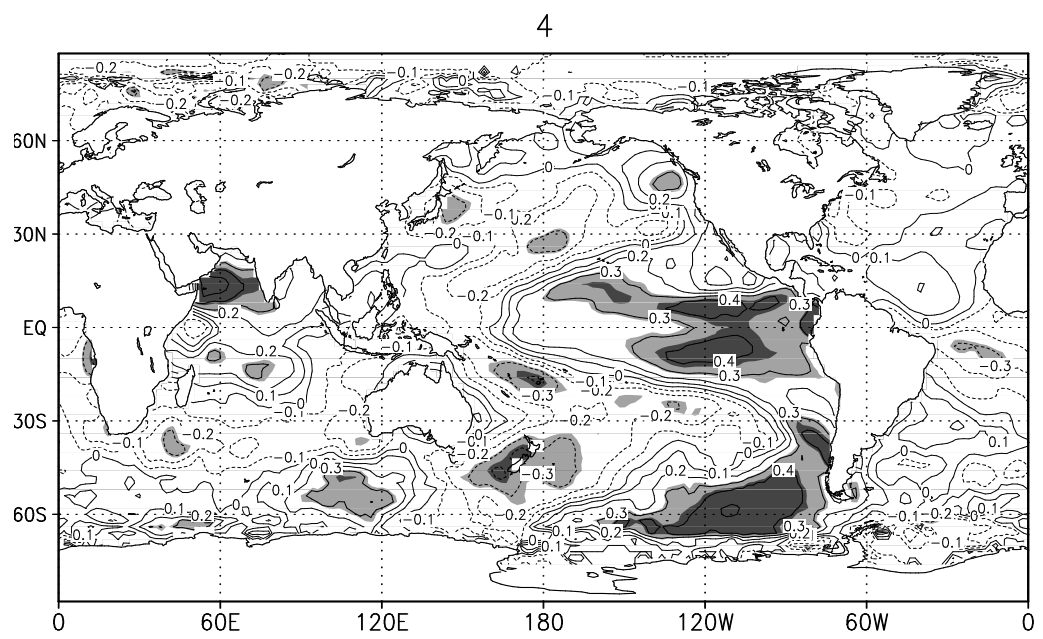

(e)

Figure 12. Time-advance/lag correlation coefficient between principal mode and responding global SSTA over the period of 1961-2006. (a) Four months prior case; (b) Two months prior case; (c) WS period; (d) Two months lag case; (e) Four months lag case. 
projects that the El Niño is getting strength from post monsoon period through early winter and achieve maximum strength, on reaching the WS period and onward dissipates as clear from Panels 12d and 12e. Therefore, the importance of ENSO indices (Niño3/Niño3.4) becomes instrumental for the appropriate WSP forecast in Pakistan.

Reference to Figure 13 the time-lag correlation coefficient between the principal mode and Niño4 Index achieves the level of significance from the previous year April through monsoon, post monsoon and gets strong correlation by chasing the month of February and March. In this context, the period that stretches over from post monsoon to early winter is most significant. Therefore, we can use the winter Niño4 index as model predictor for the WSP in Pakistan. This forecast could be highly worthy for the fruit growing regions in the rugged western terrain of the country, including the valleys of Quetta, Kalat, Zhob, Swat, Peshawar and Chitral as well as Hazara Division, GB-AK, northern Punjab and grain growing rain fed areas of the country.

\section{Second Mode with Tripole Pattern in Relation to Atmospheric Circulations}

Figure 15 represents the correlation coefficient between EOF-T2 and responding SLP, 500 hPa height, 200 hPa height and $200 \mathrm{hPa}$ zonal wind. When winter-spring precipitation has tripole anomalous pattern with negative coefficient over northwestern mountainous parts and positive coefficient over Quetta region and northeastern Punjab, the atmospheric circulation accentuates that the intensified Icelandic negative anomaly and positive anomaly over Azores region and surrounding oceans and coastal areas show the association of second significant mode with NAO. The cyclonic condition is penetrating to western Asia and CSWA from Eastern Europe at surface level.

Referred to middle tropospheric level (Panel 15b) negative pressure anomaly exists over Icelandic and Green land region also the negative anomalous patch is located over the subtropical Atlantic ocean that extends through Sahara to Middle East, side by side between the said two areas positive anomaly prevails over the subtropical Atlantic ocean with a shift toward north American. This arrangement of anomalous atmospheric state confers the western Atlantic teleconnection pattern. The belt marked by elongated trough that stretches over Sahara on to Middle East representing the upper level counter part of the surface cyclonic activity which is the potential factor to exert influence over the precipitation of the study region. At upper level (200 hPa) over the North Atlantic Ocean negative, positive and negative pattern over Icelandic region, middle latitudes and subtropical latitudes exists that is more or less analogous to the $500 \mathrm{hPa}$ anomalous pressure field. This anomalous atmospheric state confers the east Atlantic teleconnection pattern. At the level of $200 \mathrm{hPa}$ the negative anomalies over the subtropical belt from Atlantic through Sahara on to the Middle East is the counter part of surface cyclonic activity

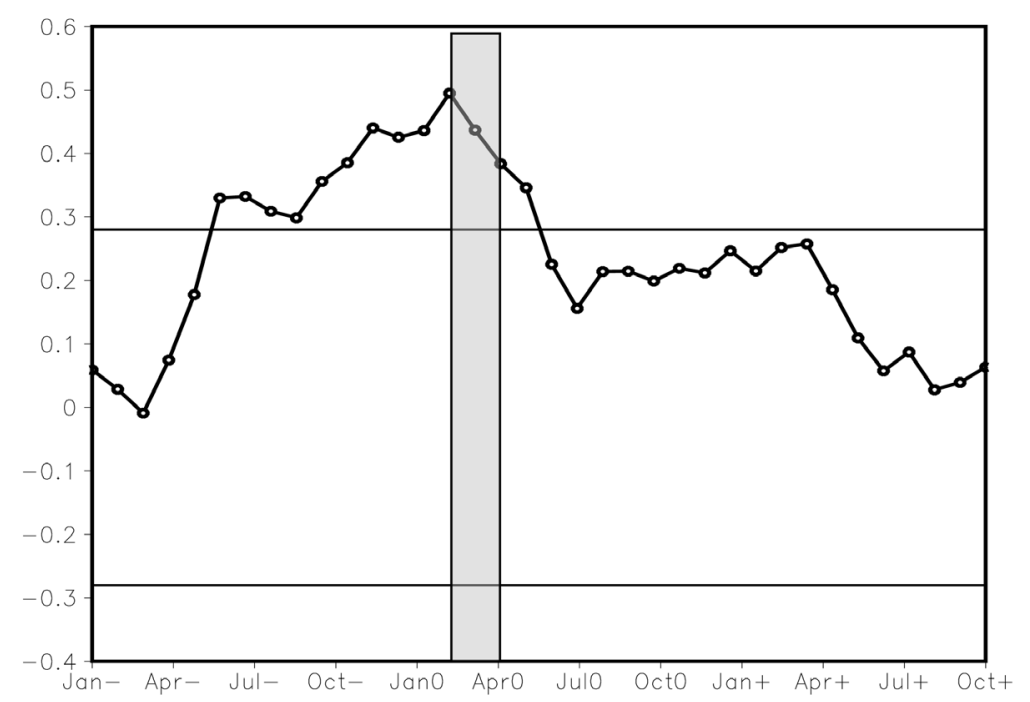

Figure 13. Time-lag correlation coefficient between the principal mode and Niño4 Index (negative/positive months indicate the advance/lag with respect to the study period (FMA); two horizontal solid lines denote 0.05 significance level; the vertical shaded column marks the study months). 


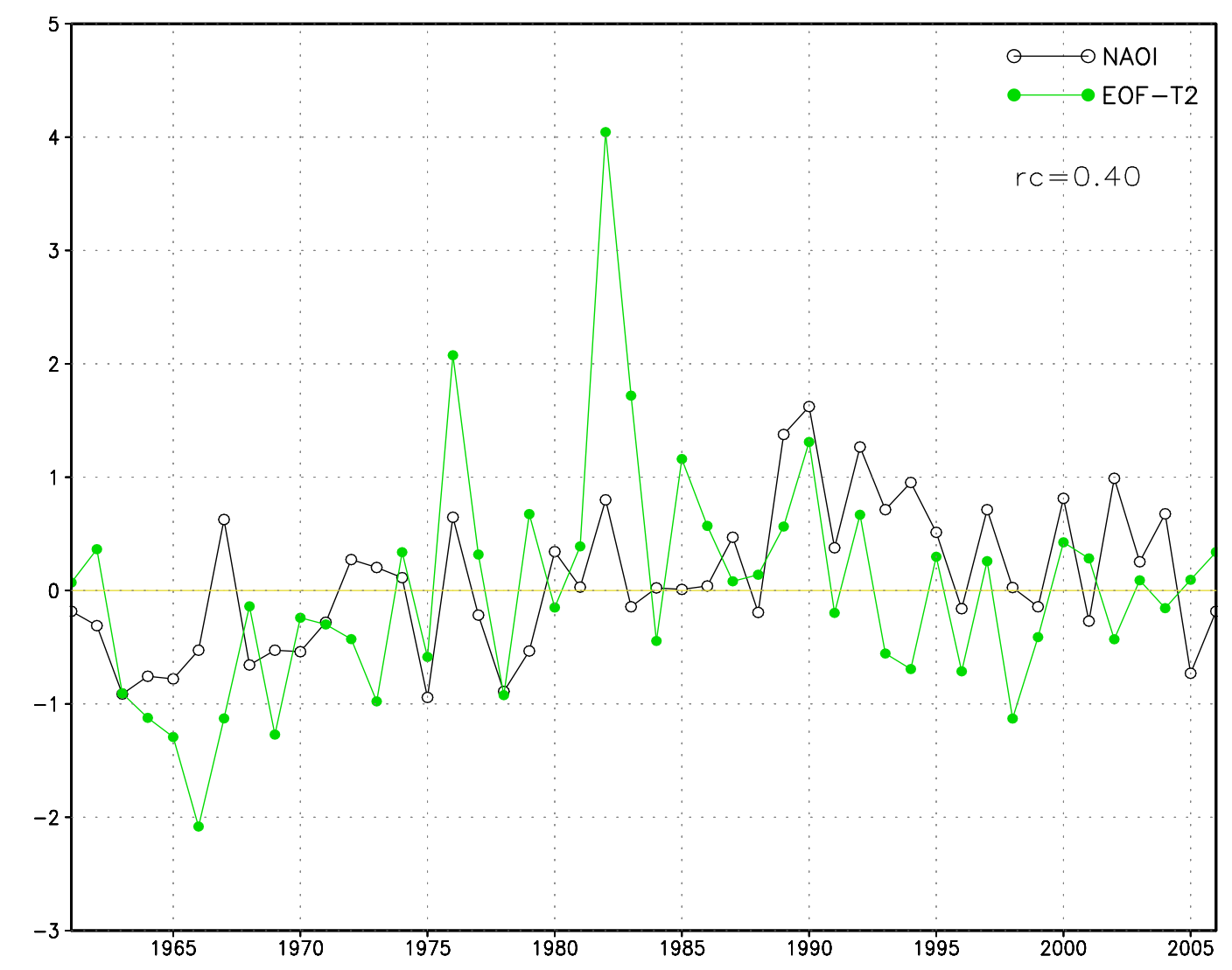

Figure 14. Relation between EOF-T2 and NAO index over the period of 1961-2006. The NAO index is the SLP difference between two stations Stykkisholmur (Iceland) and Ponta Delgada (Azores) denote Icelandic low and Azores high respectively but the respective pressure poles do not necessarily centered over these two stations.

while from Midlatitudes Atlantic on to Europe and central Asia parallel positive anomaly does exist. In the upper level zonal flow the westerly jet seems stronger over the Middle East but shifted towards west and also facing blocking condition over the subcontinent. The upper level flow indicates that it will not give birth to strong surface influence in the form of strong WDs as indicated by surface SLP over the study region and surroundings and thus reduces the chances of positive anomaly of winter-spring precipitation in the study region.

The development of WDs dependent on NAO index over the Mediterranean region deeply influences the study region by its eastwards extension. This confers relationship between NAO and existing tripole spatial anomalous WSP structure. The argument put forwarded by [32] that positive NAO brings positive winter (DJFM) precipitation anomaly over northwestern Pakistan can be accepted partially in case of winter-spring precipitation found in tripole pattern (Figure 6). In the light of the above argument, the spatial-temporal winter-spring precipitation anomalies in Pakistan are closely associated with NAO. The NAO index proved to be a good tool and capable of highlighting the relationship between NAO and climate variation at global scale [33]. The relation between NAO index and EOF-T2 is correlated by value of 0.40 and found statistically significant as well as consistent (Figure 14), the positive NAO mode increases winter-spring precipitation and vice versa in Pakistan. Simultaneously the structure of winter-spring precipitation in Pakistan can also be linked to remote annular structure of Antarctic Oscillation (AAO). If the northwestern lofty rugged territory including parts of GB-AK/KP-TA, northeastern Punjab and Quetta-Kalat region in northwestern have positive, negative and negative anomalies at the scale of interannual variability in winter-spring precipitation then we may have the atmospheric anomalies with opposite signatures than those which have been observed in Figure 8.

\section{Second Mode EOF-2 and Its Relation with SST Anomalies}

Figure 16 reveals the time-lag response of global SST anomalies in relation to EOF-2, when winter-spring preci- 


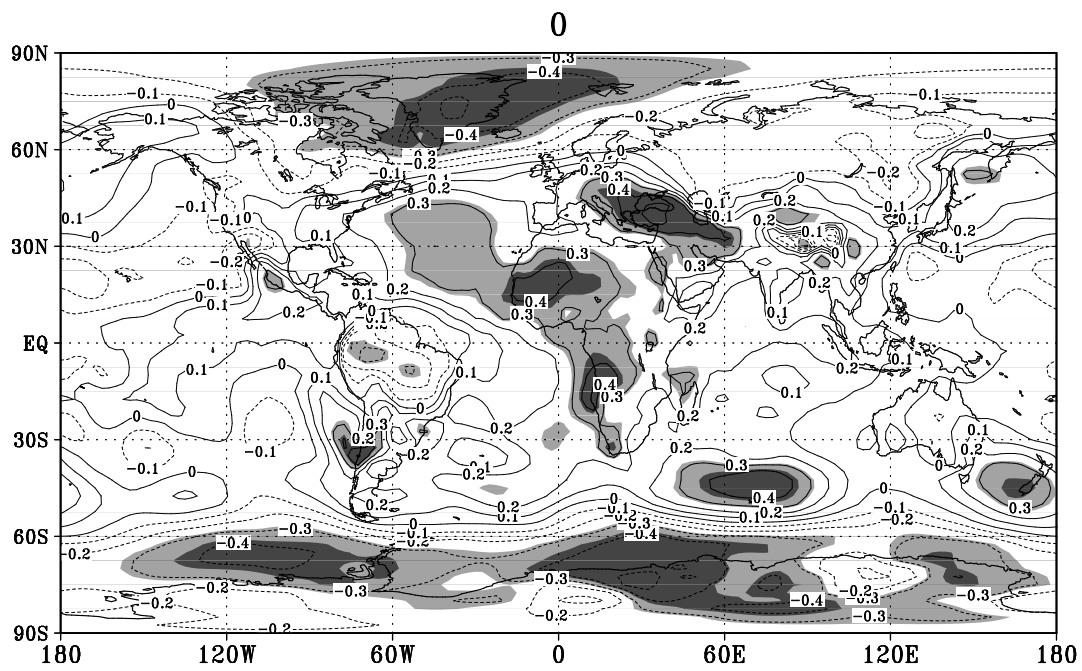

(a)

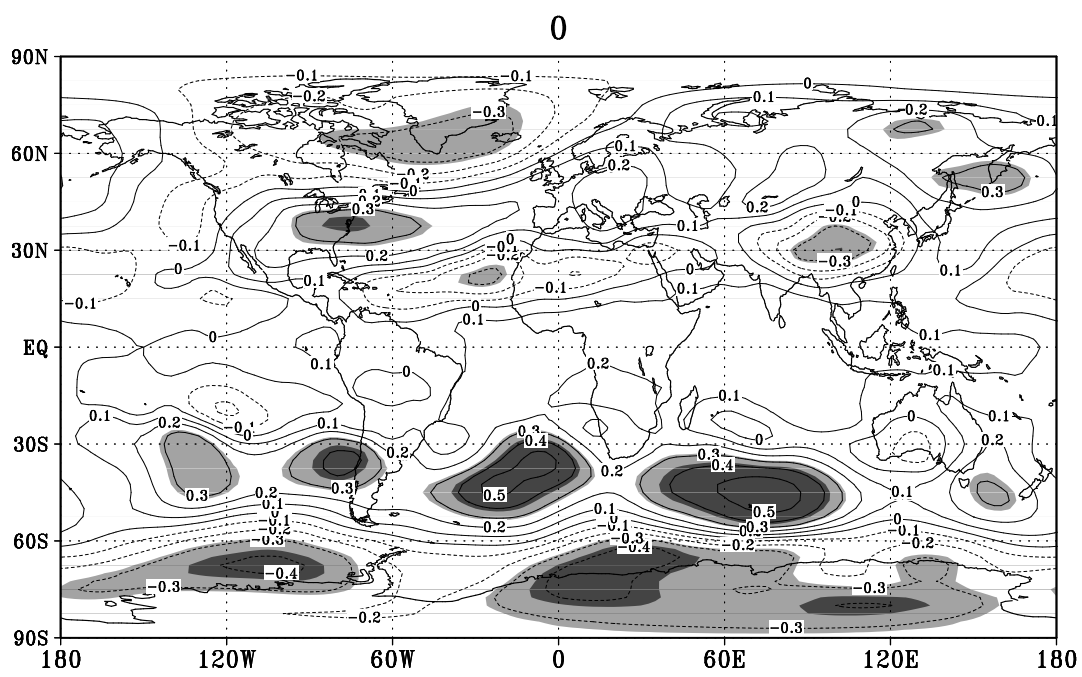

(b)

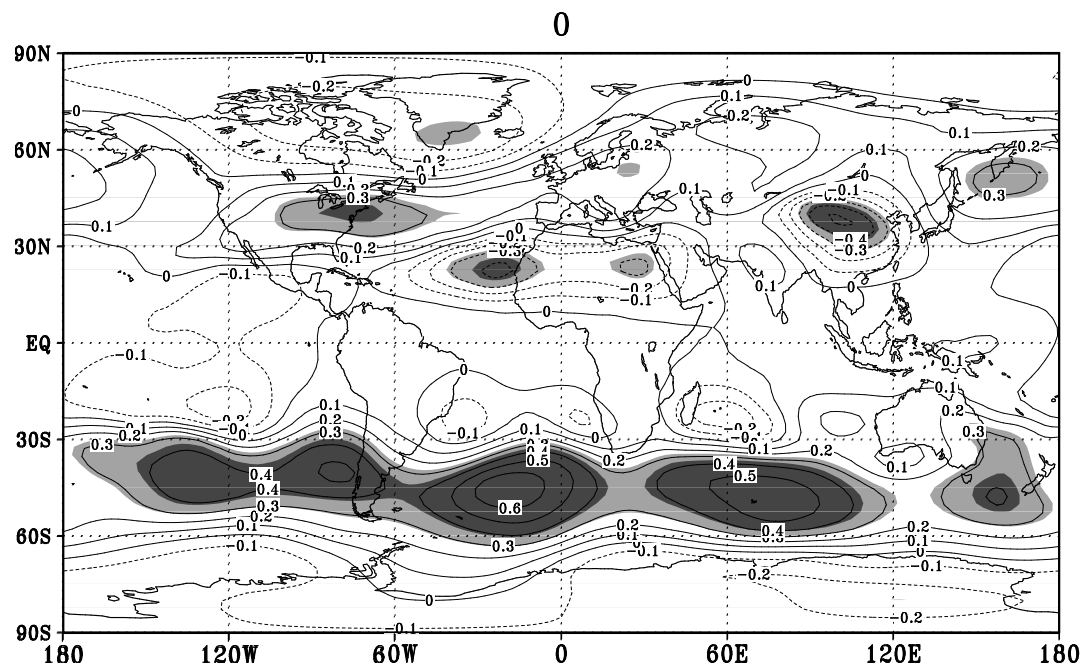

(c) 


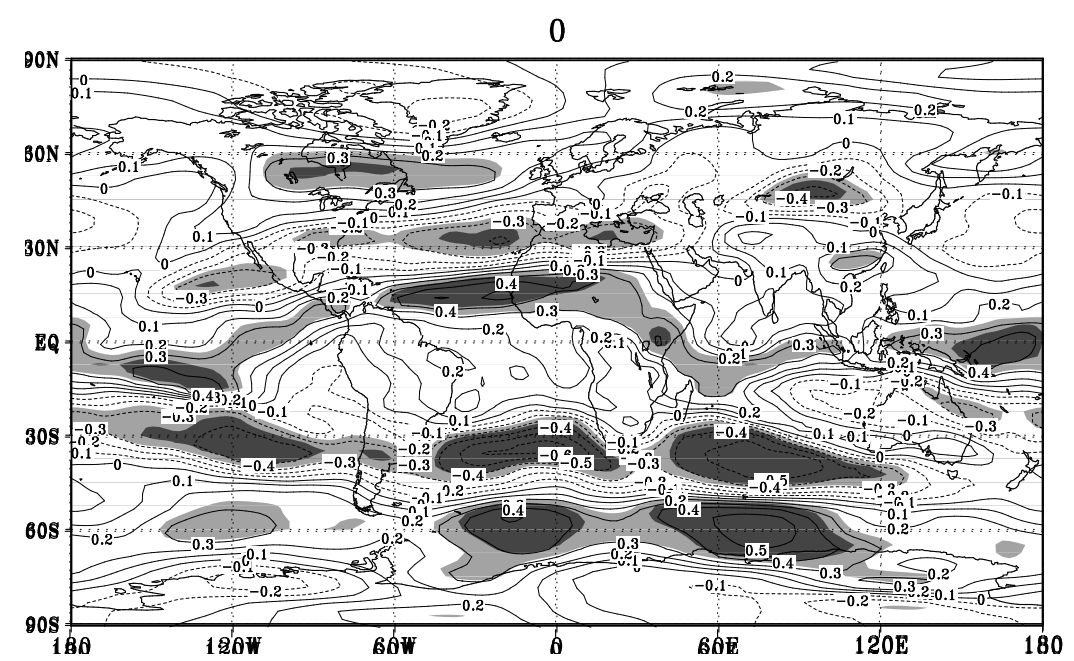

(d)

Figure 15. Correlation coefficient between EOF-T2 and responding SLP, $500 \mathrm{hPa}$ height, $200 \mathrm{hPa}$ height, $200 \mathrm{hPa}$ zonal wind.

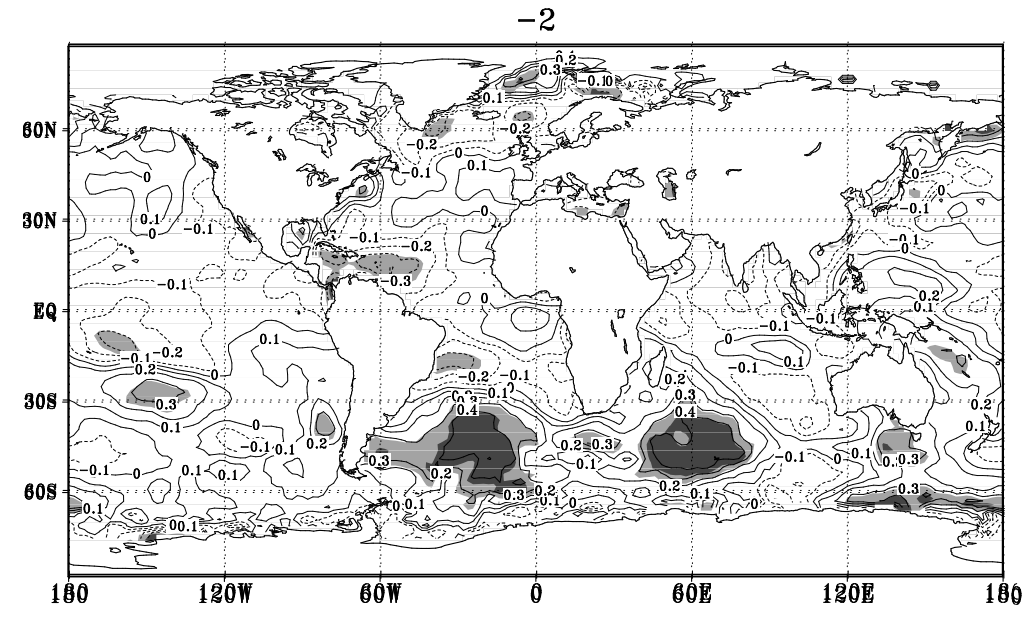

(a)

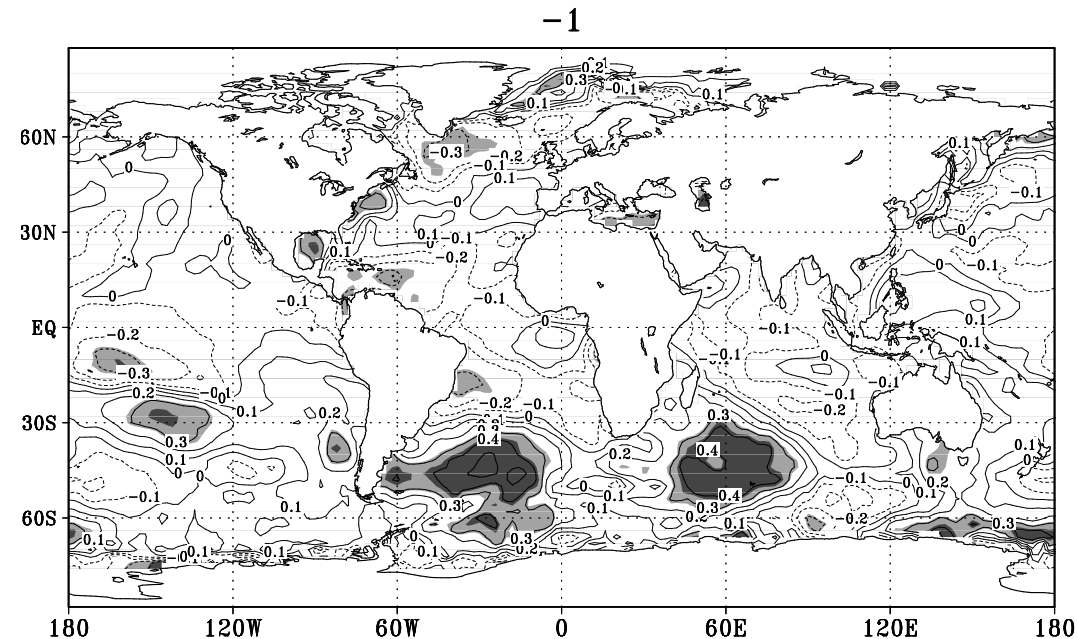

(b) 


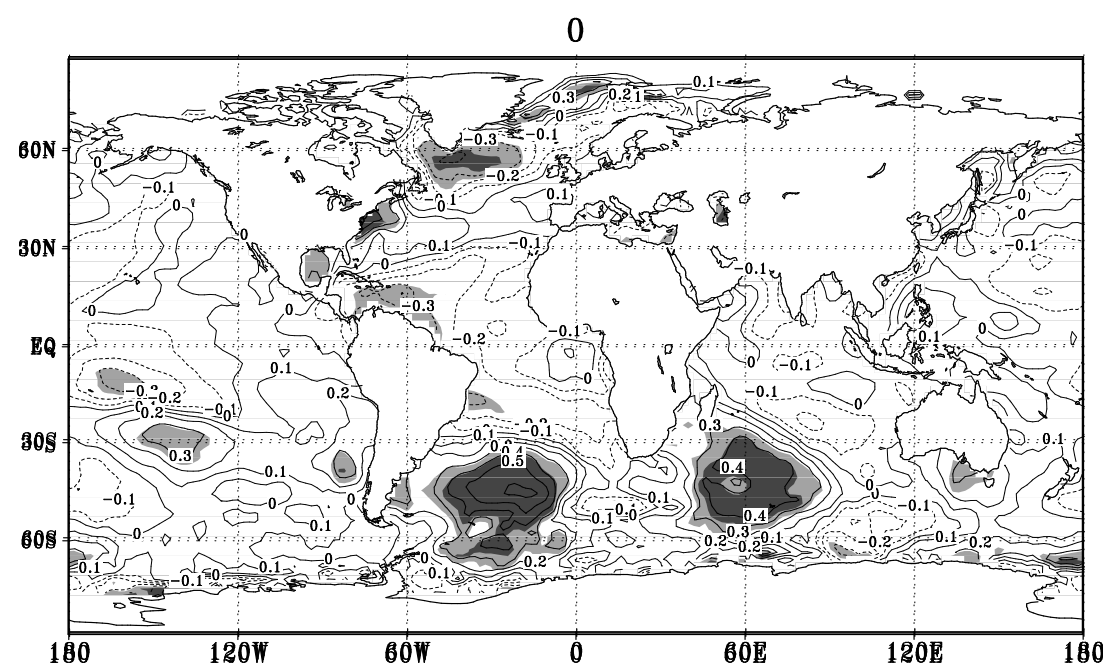

(c)

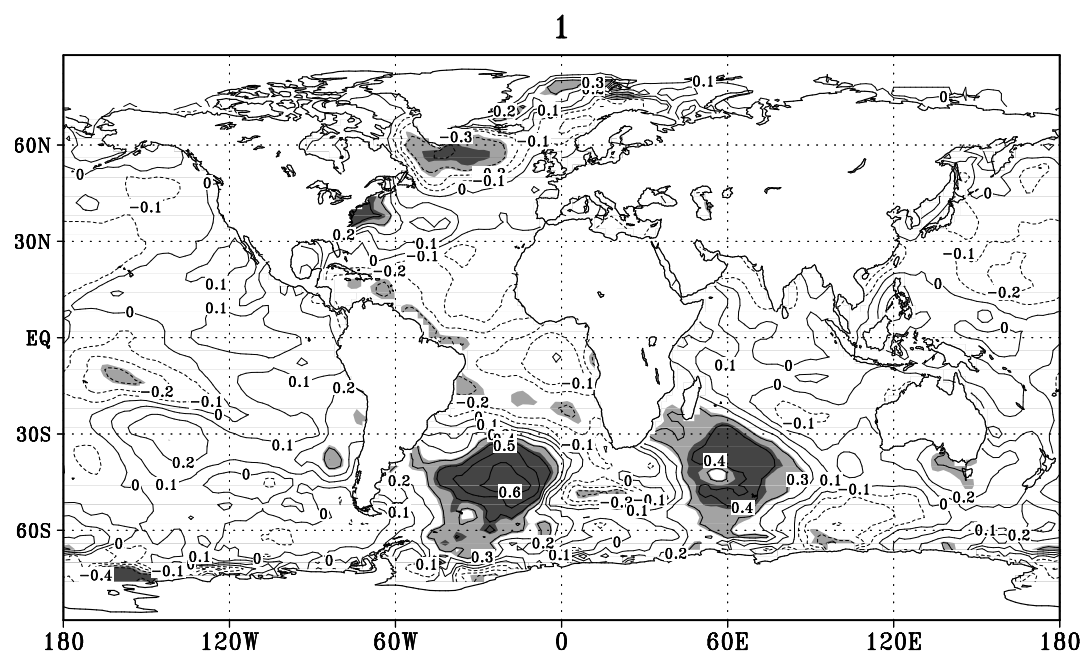

(d)

Figure 16. Time-lag correlation coefficient between EOF-T2 and responding global sea surface temperature (negative, positive) number on top of each panel indicates advance or lag by months with respect to FMA over the study period.

pitation in Pakistan has tripole anomalous structure with nodes of variability located in northwestern parts, Quetta region and northeastern Punjab (EOF-2a) with obvious interannual variability (EOF-2a and EOF-2b). In relation to this pattern the Arabian Sea, warm pool region of the western Pacific basin and adjoining Indian Ocean show no significant SST anomalies. The southern Indian and Atlantic oceans show warm and stable SST anomalies in the southern mid-latitudes of their respective basins, simultaneously SST are below normal in the Antarctic oceans (Panels 16a, 16b, 16c, 16d). Hence, the SST anomalies and lower atmospheric pressure anomalies are interdependent therefore; we assume that this type of SST anomalies indirectly shows that the tripole pattern may have relation with remote AAO. Two months and one month prior cases (Panels 16a \& 156) illustrate that the coastal areas along the western parts of northern Atlantic ocean has negative, positive and negative SST anomalies in tropical, subtropical and higher latitudes with weak signals, with the passage of time this SST response is growing in February and March (Panels 16c \& 16d). In the light of these SST anomalies, we can not connect the tripole pattern with any renowned SST mode. In case we have, tripole structure with variable centers of winter-spring precipitation over northwestern with positive coefficient and have negative coefficient over Quetta region and northeastern Punjab then in such a situation we may have opposite SST anomalies to those we observed in Figure 16. 


\section{Conclusion and Discussion}

\subsection{Conclusion}

The coupled interaction between Pacific Ocean and responding atmosphere has impact on the strength of westerly Jet and its location, eventually shape the WDs through teleconnection that intruding Pakistan from the west. Thus, the extent and intensity of this enclosed cyclonic system at low level encourages the moisture flux from the Arabian Sea which may result into positive WSP in the study area. The WSP has close link with post monsoon and early positive ENSO phase therefore Niño4 index can be used as model predictor. The second important mode is pro-NAO and also shows association with remote AAO.

\subsection{Discussion}

The warm pool region and contiguous Indian Ocean as well as the tropical and subtropical was the active area in response to the rainfall anomaly (Panel 5a), in this connection the SLP is above normal in the western tropical Pacific Ocean overwhelmingly covers the warm pool region as well as extends to the contiguous Indian Ocean and below normal in the subtropical of the eastern Pacific Ocean. Furthermore, the area of positive pressure anomaly over the Indian Ocean extends to southern proximity of Pakistan. It is pertinent to note that high over western tropical Pacific basin and low in the eastern Pacific basin ascertains the signal of SO and its link with the leading EOF mode which further has been validated by the relation of WSP and Niño4 index. The record shows that most of the ENSO events become mature in boreal winter however the case may be its evolution period matters in term of influence on remote precipitation [34]. The post monsoon and early winter El Niño are recognized worthy of forecast moreover.

The second significant pattern of WSP is tripole with negative coefficient in the northwestern rugged parts of the country, positive anomaly over Quetta region and surrounding, both these areas usually remains under the maximum concentration of precipitation from WDs, another area of precipitation above normal is centered over northeastern Punjab. The associated time amplitude reflects the interannual variability with three different interdecadal episodes, a negative phase from early 1960s to mid-1970s a positive phase from mid-1970 to late 1990s and negative phase from early 1990s and onward up to 2006. The atmospheric response at SLP manifests that second pattern is pro-NAO; the positive (negative) NAO mode encourages (discourages) winter spring precipitation in Pakistan. On the contrary, the SST anomalies in the southern global oceans which is more obvious over southern parts of Atlantic and Indian Oceans support the link of remote AAO with the tripole anomalous pattern of WSP in Pakistan. Therefore, apart of ENSO as a strong predictor the NAO and AAO could be potential predictors for WSP in Pakistan.

\section{Acknowledgements}

We are grateful to Pakistan meteorological Department (PMD) for providing the ground observed data. We highly appreciate the NCEP/NCAR and NAAO for making the data available online. The paper has been improved after the comments and suggestions given by anonymous reviewers.

\section{References}

[1] McPhaden, M.J. (1999) Genesis and Evolution of the 1997-1998 El Niño. Science, 283, 950-954. http://dx.doi.org/10.1126/science.283.5404.950

[2] Barlow, M., Cullen, H. and Lyon, B. (2002) Drought in Central and Southwest Asia: La Nina, the Warm Pool, and Indian Ocean Precipitation. Journal of Climate, 15, 697-700. http://dx.doi.org/10.1175/1520-0442(2002)015<0697:DICASA>2.0.CO;2

[3] Trenberth, K.E., Jones, P.D., Ambenje, P., Bojariu, R., Easterling, D., Klein Tank, A., Parker, D., Rahimzadeh, F., Renwick, J.A., Rusticucci, M., Soden, B. and Zhai, P. (2007) Observations: Surface and Atmospheric Climate Change. In: Climate Change 2007: The Physical Science Basis. Contribution of Working Group I to the Fourth Assessment Report of the Intergovernmental Panel on Climate Change [Solomon, S., Qin, D., Manning, M., Chen, Z., Marquis, M., Averyt, K.B., Tignor, M. and Miller, H.L., Eds.]. Cambridge University Press, Cambridge and New York.

[4] Chen, C.-C., Mccarl, B. and Hill, H. (2002) Agricultural Value of ENSO Information under Alternative Phase Definition. Climatic Change, 54, 305-325. http://dx.doi.org/10.1023/A:1016160218221

[5] Population Reference Bureau (PRB) (2008) http://www.prb.org 
[6] Archer David, R. and Fowler Haley, J. (2004) Spatial and Temporal Variations in Precipitation in the Upper Indus Basin, Global Teleconnections and Hydrological Implications. Hydrology and Earth System Sciences, 8, 47-61. http://dx.doi.org/10.5194/hess-8-47-2004

[7] Trewratha, G.T. (1961) The Earth’s Problem Climate. University of Wisconsin Press, Madison, 244-247.

[8] Pisharoty, P.R. and Desai, B.N. (1956) Western Disturbances and Indian Weather. Indian Journal of Meteorology and Geophysics, 8, 333-338.

[9] Rao, Y.P. and Srinivasan, V. (1969) IMD FMU Report-III, 1.1, 40.

[10] Dutta, R.K. and Gupta, M.G. (1967) Synoptic Study of the Formation and Movement of Western Depression. Indian Journal of Meteorology and Geophysics, 18, 45.

[11] Agnihotri, C.L. and Singh, M.S. (1982) Satellite Study of Western Disturbances. Mausam, 33, 249-254.

[12] Singh, M.S. (1963) Upper Air Circulation Associated with a Western Depression. Indian Journal of Meteorology and Geophysics, 14, 156.

[13] Mooley, D.A. (1957) The Role of Western Disturbances in the Production of Weather over India during Different Seasons. Indian Journal of Meteorology and Geophysics, 8, 253-260.

[14] Martyn, D. (1992) Climates of the World. Elsevier, Amsterdam, 436 p.

[15] Dimri, A.P. (2006) Surface and Upper Air Fields during Extreme Winter Precipitation over the Western Himalayas. Pure and Applied Geophysics, 163, 1679-1698. http://dx.doi.org/10.1007/s00024-006-0092-4

[16] Khan, T.M.A., Quadr, D.A., Murty, T. and Sarker, M.A. (2004) Seasonal and Interannual Sea Surface Temperature Variability in the Coastal Cities of Arabian Sea and Bay of Bengal. Natural Hazards, 31, 549-560. http://dx.doi.org/10.1023/B:NHAZ.0000023367.66009.1d

[17] Kumar, K.K., Rajagopalan, B., Hoerling, M., Bates, G. and Cane, M. (2006) Unraveling the Mystery of Indian Monsoon Failure during El Niño. Science, 314, 115-119. http://dx.doi.org/10.1126/science.1131152

[18] Kumar, K.K., Rajagopalan, B. and Cane, M.A. (1999) On the Weakening Relationship between the Indian Monsoon and ENSO. Science, 284, 2156-2159. http://dx.doi.org/10.1126/science.284.5423.2156

[19] Torrence, C. and Webster, P.J. (1999) Interdecadal Changes in the ENSO-Monsoon System. Journal of Climate, 12, 2679-2690. http://dx.doi.org/10.1175/1520-0442(1999)012<2679:ICITEM>2.0.CO;2

[20] Zhu, W.J. and Sun, Z.B. (1999) Influence of ENSO Event on the Maintenance of Pacific Storm Track in the Northern Winter. Advance in Atmospheric Sciences, 16, 630-640. http://dx.doi.org/10.1007/s00376-999-0037-9

[21] Marshall, J., Kushnir, Y., Battisti, D., Chang, P., Czaja, A., Dickson, R., et al. (2001) North Atlantic Climate Variability: Phenomena, Impacts and Mechanisms. International Journal of Climatology, 21, 1863-1898.

[22] Li, J. and Wang, J. (2003) A New North Atlantic Oscillation Index and Its Variability. Advance in Atmospheric Sciences, 20, 661-676. http://dx.doi.org/10.1007/BF02915394

[23] Hurrell, J.W. (1996) Influence of Variations in Extratropical Wintertime Teleconnections on Northern Hemisphere Temperatures. Geophysical Research Letters, 23, 665-668. http://dx.doi.org/10.1029/96GL00459

[24] Hurrell, J.W. (1995) Decadal Trends in the North Atlantic Oscillation: Regional Temperatures and Precipitation. Science, 269, 676-679. http://dx.doi.org/10.1126/science.269.5224.676

[25] Walker, G.T. and Bliss, E.W. (1932) World Weather V. Memoirs of the Royal Meteorological Society, 4, 53-84.

[26] Achuthavarier, D. and Krishnamurthy, V. (2009) Relation between Intraseasonal and Interannual Variability of South Asian Monsoon in the NCEP Forecast System. Cola Technical Report 285, August 2009.

[27] Kalnay, E., Kanamitsu, M., Kistler, R., Collins, W., Deaven, D., Gandin, L., et al. (1996) The NCEP/NCAR 40-Year Reanalysis Project. Bulletin of the American Meteorological Society, 77, 437-470. http://dx.doi.org/10.1175/1520-0477(1996)077<0437:TNYRP>2.0.CO;2

[28] Smith, T.M., Reynolds, R.W., Peterson, T.C. and Lawrimore, J. (2008) Improvements to NOAA’s Historical Merged Land-Ocean Surface Temperature Analysis (1880-2006). Journal of Climate, 21, 2283-2296. http://dx.doi.org/10.1175/2007JCLI2100.1

[29] Syed, F.S., Giorgi, F., Pal, J.S. and King, M.P. (2006) Effect of Remote Forcings on the Winter Precipitation of Central Southwest Asia Part 1: Observations. Theoretical and Applied Climatology, 86, 147-160. http://dx.doi.org/10.1007/s00704-005-0217-1

[30] Mo, R.P., Fyfe, J. and Derome, J. (1998) Phase-Locked and Asymmetric Correlations of the Wintertime Atmospheric Patterns with the ENSO. Atmosphere-Ocean, 36, 213-239. http://dx.doi.org/10.1080/07055900.1998.9649612

[31] Chen, W.Y. and van den Dool, H.M. (1999) Significant Change of Extratropical Natural Variability and Potential Predictability Associated with the El Niño/Southern Oscillation. Tellus, 51A, 790-802. 
http://dx.doi.org/10.1034/j.1600-0870.1999.00017.x

[32] Fu, C.B. and Teng, X.L. (1988) Relationship between Summer Climate in China and El Niño/Southern Oscillation Phenomenon. Chinese Journal of Atmospheric Sciences, 12, 133-141. (In Chinese)

[33] Li, J. and Wang, J. (2003) A New North Atlantic Oscillation Index and Its Variability. Advances in Atmospheric Sciences, 20, 661-676. http://dx.doi.org/10.1007/BF02915394

[34] Wang, H. and Liu, Q.Y. (2014) Boreal Winter Rainfall Anomaly over the Tropical Indo-Pacific and Its Effect on Northern Hemisphere Atmospheric Circulation in CMIP5 Model. Advances in Atmospheric Sciences, 31, 916-925. 